\title{
Integrating conflict, lobbying, and compliance to predict the sustainability of natural resource use
}

\author{
$\underline{\text { Jeremy J. Cusack }}^{1,2}, \underline{\text { A. Bradley Duthie }}^{1}, \underline{\text { Jeroen Minderman }}^{1}, \underline{\text { Isabel L. Jones }}^{1}, \underline{\text { Rocío A. Pozo }}^{1,3}, \underline{\text { O. Sarobidy Rakotonarivo }}^{1}, \underline{\text { Steve }}$ \\ $\underline{\text { Redpath }}^{4}$ and Nils Bunnefeld ${ }^{1}$
}

\begin{abstract}
Predictive models are sorely needed to guide the management of harvested natural resources worldwide, yet existing frameworks fail to integrate the dynamic and interacting governance processes driving unsustainable use. We developed a new framework in which the conflicting interests of three key stakeholders are modeled: managers seeking sustainability, users seeking increases in harvest quota, and conservationists seeking harvest restrictions. Our model allows stakeholder groups to influence management decisions and illegal harvest through flexible functions that reflect widespread lobbying and noncompliance processes. Decision making is modeled through the use of a genetic algorithm, which allows stakeholders to respond to a dynamic social-ecological environment to satisfy their goals. To provide the critical link between conceptual and empirical approaches, we compare predictions from our model against data on 206 harvested terrestrial species from the IUCN Red List. We show that, although lobbying for a ban on resource use can offset low levels of noncompliance, such bias leads to an increased risk of extinction when noncompliance (and therefore illegal harvesting) is high. Management decisions unaffected by lobbying, combined with high rule compliance, resulted in more sustainable resource use. Model predictions were strongly reflected in our analysis of harvested IUCN species, with $81 \%$ of those classified under regulated harvest and high compliance showing stable or increasing population trends. Our results highlight the fine balance between maintaining compliance and biasing decisions in the face of lobbying. They also emphasize the urgent need to quantify lobbying and compliance processes across a range of natural resources. Overall, our work provides a holistic and versatile approach to addressing complex social processes underlying the mismanagement of natural resources.
\end{abstract}

Key Words: conservation; decision making; genetic algorithm; governance; harvest regulation; IUCN; management strategy evaluation; population target; trend; user; wildlife

\section{INTRODUCTION}

In the midst of the sixth mass extinction (Ceballos et al. 2017), sustainable use of the world's natural resources, including wildlife, fish stocks, and timber, has become critical (Di Minin et al. 2019, Ripple et al. 2019). Key to achieving sustainability is the development of flexible quantitative models with which to evaluate the consequences of alternative harvest management scenarios, and in turn support decision making and policy implementation (Shea and the NCEAS Working Group on Population Management 1998, Schmolke et al. 2010, Bunnefeld et al. 2017). Although there is now broad consensus that such models should integrate both the social and ecological processes inherent to resource management systems (Milner-Gulland 2012, Sayles et al. 2019, Schlüter et al. 2019a, b), the resulting complexity remains daunting (Folke et al. 2010, Bunnefeld et al. 2017). A major challenge concerns how to best integrate governance processes and human behavior into existing management models in a way that optimizes predictive accuracy whilst minimizing complexity (Müller-Hansen et al. 2017, Schlüter et al. 2019a, Travers et al. 2019a), and improves applicability to a broad spectrum of harvesting systems.

Governance relates to the societal context and processes that shape collective decision making and action (Bevir 2012). The term governance is used very broadly across disciplines, but within the context of natural resource use it typically describes the interactive processes occurring among different stakeholders through which decisions relating to resource harvest and management are made (Lockwood et al. 2010, Cox et al. 2016).
Although collective governance, sometimes referred to as comanagement, is often sought (Armitage et al. 2009), this is often impeded by conflicts occurring among stakeholders with diverging interests (Redpath et al. 2013, Orach and Schlüter 2016, Bodin 2017, Cumming 2018), such as the exploitation versus the conservation of a natural resource (Benítez-López et al. 2017). Such conflicts are widespread and pose a major threat to the sustainable use of natural resources worldwide. In spite of this, our ability to integrate the governance processes through which conflicts operate into existing sustainable management frameworks is currently very limited.

A common symptom of conflicts surrounding the use of natural resources is illegal harvesting behavior, whereby resource users do not comply with harvesting rules and regulations, e.g., quotas. Although individual economic and social drivers of noncompliance have received increased attention over the last decade (Keane et al. 2008, Gavin et al. 2010, Solomon et al. 2015, Duffy et al. 2016, Travers et al. 2019b), the behavior of resource users in relation to other complex and dynamic governance processes currently lacks theoretical and empirical support. One such process is lobbying, through which interest groups seek to directly influence management decision making to bias outcomes in their favor (Baumgartner et al. 2009, Lute and Gore 2014, Meng and Rode 2019). Lobbying may attempt to advance the interests of natural resource users, for example, those of commercial industries in the case of marketable natural resources (Murray 2003). It may also serve the interests of parties seeking to restrict resource use, such as conservation organizations (Mace 2014,

${ }^{1}$ Biological and Environmental Sciences, University of Stirling, Stirling, UK, ${ }^{2}$ Center for Ecosystem Modeling and Monitoring, Universidad Mayor, Santiago, Chile, ${ }^{3}$ Center for Climate and Resilience Research (CR2), Santiago, Chile, ${ }^{4}$ University of Aberdeen, Aberdeen, UK 
Adams 2017, Baynham-Herd et al. 2018, Challender and MacMillan 2019). In this latter case, lobbying to impose restrictions on the use of a natural resource could exacerbate illegal harvesting pressure (Di Minin et al. 2016), particularly if the resource is economically valuable, e.g. rhino horn (Biggs et al. 2013) or culturally important, e.g., agarwood from Aquilaria sinensis (Chen et al. 2019). In turn, noncompliance with harvesting rules may trigger more intense lobbying, not only from conservation interest groups, but also from resource user groups that do harvest legally, thereby creating feedback processes affecting resource management. Yet, despite the huge potential for the combined and interlinked effects of conflict, noncompliance, and lobbying to destabilize sustainable natural resource use, no modeling frameworks, to our knowledge, have explicitly accounted for them.

State-of-the-art modeling frameworks to optimize natural resource management have been particularly well developed in the context of commercial fisheries, where harvest allocation is typically based on close monitoring of fish stocks and catches (Audzijonyte et al. 2019). One such framework, known as management strategy evaluation (MSE; Smith et al. 1999, Punt et al. 2016, Stephenson et al. 2017), enables the entire management system, including stock dynamics and monitoring, management decisions, and harvesting activities, to be simulated in search of a strategy that best addresses management objectives. A key feature of MSE is its ability to explicitly model the uncertainty surrounding individual management components (MilnerGulland and Shea 2017), such as stock stochasticity, monitoring error, decision biases, or illegal behavior by harvesters. Using a fisheries example, Armitage et al. (2019) recently advocated the widespread integration of governance processes into MSE frameworks, highlighting in particular the existence of decisionmaking thresholds (Harford et al. 2016).

In contrast, the development of flexible, MSE-based frameworks encompassing more realistic processes of decision making and human behavior has been largely absent from terrestrial harvesting systems (Bunnefeld et al. 2011, Bunnefeld and MilnerGulland 2016, Moa et al. 2017). Indeed, modeling frameworks to date have focused disproportionately on the ecological dimension of terrestrial harvesting systems (Gamelon et al. 2019), such as the development of elaborate population and community response models, e.g. to trophy hunting (Whitman et al. 2007, Loveridge et al. 2016) or the assessment of harvest-induced evolution (Kuparinen and Festa-Bianchet 2017). Although often presented within an adaptive management framework (Kolbe et al. 2017, Andrén et al. 2020), these approaches tend to overlook how the implementation of management decisions can be perturbed by conflicts of interest. Predictive models that can include these governance processes are now sorely needed to guide the management of terrestrial harvesting systems (Bunnefeld et al. 2011, 2017, Dobson et al. 2019), in which mismanagement and overharvesting have become widespread (Díaz et al. 2019).

In this study, we develop a flexible and widely applicable form of MSE model in which the interests of three different stakeholders are considered: managers seeking sustainability, users seeking increases in quota, and conservationists seeking harvest restrictions. All stakeholder groups are able to influence management decisions and users can harvest illegally through the implementation of flexible and dynamic functions that govern lobbying and noncompliance processes. Unlike typical MSE models that represent human behavior through scenario-based and static actions, we optimize decision making through the use of a genetic algorithm, which allows stakeholders to respond to a dynamic social-ecological environment to satisfy their (potentially divergent) goals. Using this modeling framework, we first derive general predictions regarding natural resource management sustainability in the presence of stakeholder conflicts. We then demonstrate the ability of our model to predict population trend patterns observed across a range of harvested vertebrate species from terrestrial systems. By combining existing aspects of MSE models with functions describing governance processes driven by conflicting stakeholder goals, our framework enables comparison of management strategies within a more realistic and dynamic social-ecological setting.

\section{METHODS}

\section{Modeling framework}

Management strategy evaluation models typically comprise four submodels, each representing one component of the management system (Fig. 1a; Bunnefeld et al. 2011, Punt et al. 2016). In most cases, a population submodel, which simulates the dynamics of the natural resource population under harvest, produces a "true" value of resource abundance at time step $t$. A monitoring submodel subsequently simulates an observation process through which an estimate of resource abundance, along with associated uncertainty, is obtained. This estimate is then passed on to a manager submodel, whose role is to turn the observation into a harvesting policy that is aligned with the manager's objective (also called a performance metric). The resulting policy is then acted on by a harvesting submodel, which determines the final off-take from the resource population. This cycle can be repeated over a desired number of time steps, thus enabling dynamic processes to be considered when predicting management outcomes over both short and long time frames.

For the purpose of this study, the population submodel consists of a simple discrete logistic resource growth model of the form,

$$
N(t+1)=\frac{N(t) K e^{r(t)}}{K+N(t)\left(\mathrm{e}^{r(t)}-1\right)}-H(t)
$$

in which $N(t)$ is the resource population size at time $t, K$ its carrying capacity, $r(t)$ its growth rate at $t$, and $H(t)$ the total harvest at $t$ (combining legal and illegal off-takes, see below). Stochasticity is included in the model by sampling from a normal distribution with mean $r$ (the intrinsic growth rate of the population) and standard deviation $\sigma$. We further assume that the observation process as implemented within the observation submodel bears no error, i.e., the resource population size is estimated perfectly by the manager.

The observed resource population size $N(t)$ is passed on to the manager submodel, whose role is to enact a harvesting quota $Q$ ( $t$ ) that best minimizes deviations from the manager-specific target abundance $\left(N_{M}\right)$. We choose here to focus on resource abundance as a performance metric because it is a common benchmark in the management of harvested species (Sanderson 2006, Serrouya et al. 2011, Blanchard et al. 2014), but also because it facilitates understanding of our model. Choice of harvest quota 
Fig. 1. Overview of the generalized management strategy evaluation (GMSE) approach used in this study.
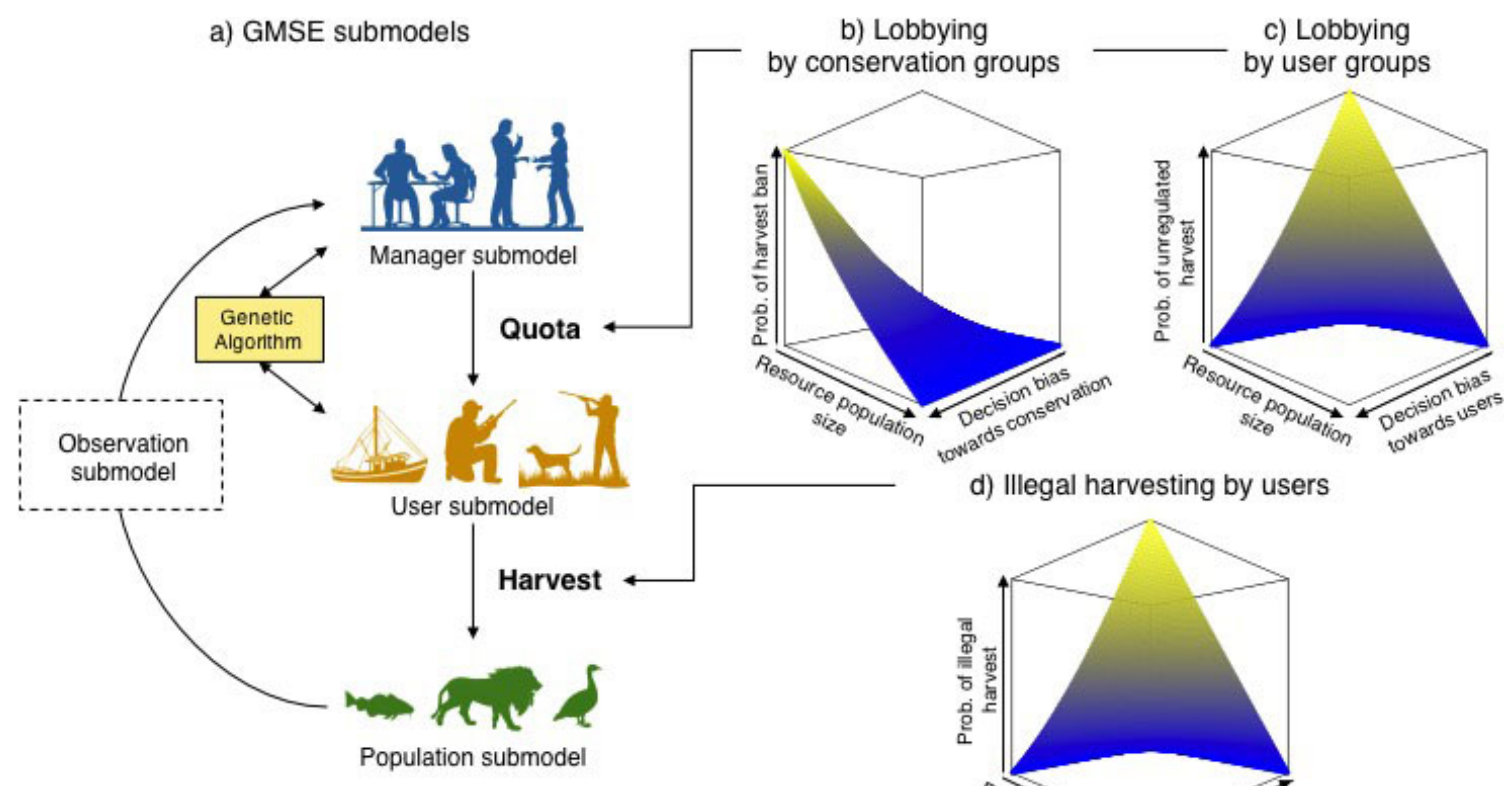

d) Illegal harvesting by users

by the manager is implemented using a genetic algorithm that finds an adaptive, but not necessarily optimal, policy, thereby mimicking a goal-oriented process prone to human error (see Duthie et al. 2018 for more details). The resulting quota is then transferred to the harvest submodel, which also calls a genetic algorithm to determine a harvest that minimizes deviation from a user-specific target abundance $\left(N_{U}\right)$ whilst taking into account varying levels of user budget (Appendix 1, Fig. A1.1).

\section{Simulating conflict}

Conflict within our MSE model can be conceptualized as assigning different objectives between manager and users with respect to $N(t)$, which the relevant submodels then attempt to optimize. To increase realism, however, we also include another key actor, conservation groups, whose primary interest in management scenarios is often to promote protection of the resource by restricting harvest. In particular, such groups may impose considerable pressure on decision makers in the form of lobbying (Sandbrook 2017). More specifically, we assume that (i) managers aim to maintain a sustainable population of a given natural resource over the period of management, i.e., achieve an average growth rate of zero, (ii) user groups seek unregulated harvest of the resource, prioritizing year on year versus long-term harvest, and (iii) conservation groups seek to ban harvesting altogether (Aryal et al. 2018), enabling the resource population to grow to carrying capacity. The objectives of users and conservationists represent opposed extremes, which is useful for conceptualizing conflicts related to natural resource use (Redpath et al. 2013). We note, however, that these can be adapted to any scenario at hand.

In the following sections, we detail how stakeholders in our model attempt to meet their respective objectives. To do this, we define two metrics that underlie levels of lobbying and illegal harvesting. The first is decision-making bias, defined as whether management decisions are biased in favor of user or conservation interests. The second is user compliance with harvesting rules, which governs the level of illegal harvesting. We note that our approach does not distinguish between the different drivers of user compliance, such as increased enforcement or monetary incentives (Cooney et al. 2017), but instead serves as a general model of behavioral change.

\section{Lobbying function}

In the model, decision making by the manager can be affected by a lobbying process representing pressure from either conservation or user interest groups (Fig. 1b and c, respectively). Lobbying pressure at time $t$ represents the probability that the manager will disregard the original, unbiased quota derived from the genetic algorithm, i.e., $Q(t)$, and instead allow either unregulated harvesting (under user lobbying) or ban harvesting altogether (under conservationist lobbying). For simplicity, decision-making biases as a result of user and conservationist lobbying are simulated separately.

For conservationists, the probability of successful lobbying for a harvesting ban is modeled as a function of how far the observed resource abundance is from the stated conservation target $\left(N_{C}\right)$ and of fixed levels of decision-making bias $\left(I_{C}\right)$ toward conservation interests. $I_{C}$ can be varied between $I_{C}=0$ (manager completely biased) and $I_{C}=1$ (manager completely unbiased). We further assume that lobbying pressure is nonexistent when $N$ $(t) \geq N_{C}$, but expect it to increase exponentially as the resource population approaches extinction $(N(t) \rightarrow 0)$. Thus, the probability of successful lobbying for a harvesting ban by conservation groups is defined as follows, 


$$
\phi_{\text {conservation }}(t)=\left[\left(2-I_{C}\right)^{\frac{N_{C}-N(t)}{N_{C}}}\right]-1
$$

$Q^{\prime}(t)$, which represents $Q(t)$ postlobbying, is then determined using a single Bernouilli trial $X(t) \sim B\left(1, \Phi_{\text {Conservation }}(\mathrm{t})\right)$ such that if $X(t)=0, Q^{\prime}(t)=Q(t)$, and if $X(t)=1, Q^{\prime}(t)=0$.

For users, the probability of successful lobbying for unregulated harvest is modeled as a function of how far the observed resource abundance is from the stated user target $\left(N_{U}\right)$ and, similarly to conservation lobbying, decision-making bias toward user interests (denoted as $I_{U}$ ). We further assume that lobbying pressure is nonexistent when $N(t) \leq N_{U}$, but expect it to increase exponentially as the resource population approaches carrying capacity $(N(t) \rightarrow K)$. Thus, the probability of successful lobbying for unregulated harvest by user groups is defined as,

$$
\phi_{U s e r}(t)=\left[\left(2-I_{U}\right)^{\frac{N(t)-N_{U}}{K-N_{U}}}\right]-1
$$

As above, $Q^{\prime}(t)$ is then determined with a Bernouilli trial $X(t) \sim$ $B\left(1, \Phi_{U s e r}(\mathrm{t})\right)$, such that if $X(t)=0, Q^{\prime}(t)=Q(t)$, and if $X(t)=$ 1 then $Q^{\prime}(t)=H_{\text {max }}(\mathrm{t})$, where $H_{\text {max }}(\mathrm{t})$ is the maximum number of individual resources that can be harvested at time $t$ given the user budget $B_{U}(\mathrm{t})$ and minimum cost of a harvest $c_{\min }$, i.e.,

$$
H_{\max }(t)=\frac{B_{U}(t)}{C_{\min }}
$$

$Q^{\prime}(t)$ subsequently determines how many units of the resource population the user can harvest legally. Both $N_{C}$ and $N_{U}$ can be varied between zero and $K$, the resource population carrying capacity.

\section{Illegal harvesting function}

The user can then choose to either implement the legal quota or harvest illegally, depending on which option maximizes harvest (Fig. 1d). In a similar way to lobbying, illegal harvesting pressure represents the probability that the user will successfully remove one unit from the resource population, and is defined as,

$$
\Psi(t)=\left[(2-E)^{\frac{N(t)-N_{U}}{K-N_{U}}}\right]-1
$$

$E$ is user compliance with harvesting rules and is varied in simulations from $E=0$ (no compliance) and $E=1$ (complete compliance). A hypothetical illegal harvest, $Y(t)$, is then derived from a Bernouilli trial $Y(t) \sim B\left(H_{\text {max }}, \Psi(\mathrm{t})\right)$. The user then implements a final harvest $H(t)$, defined as the maximum of either $Q^{\prime}(t)$ or $Y(t)$.

\section{Simulation and statistical analysis}

Model simulations were carried out in $\mathrm{R}$ (version 3.4.3) using the package GMSE (version 0.4.0.11; Duthie et al. 2018). The $\mathrm{R}$ code used to produce simulations is provided in Appendix 2, and the definition and values for set and derived parameters are presented in Appendix 3, Table A3.1. Resource population size at $t=0$ was set to 1000 units and the carrying capacity at 2000. We ran simulations for three values of $r-0.1,0.2$, and 0.3 (with $\sigma=r / 10$ in all cases) - because these represented a range of commonly measured intrinsic growth rates in the harvested species considered in our empirical analysis (see below; Sibly and Hone 2002). We varied decision-making bias ( $I$, separately for conservation and user groups) and user compliance levels $(E)$ to control lobbying and illegal harvesting levels during each time step, respectively. For each combination, we ran 100 management iterations, each lasting 10 time-steps, i.e. years. We chose to carry out simulations over 10 time steps because this was representative of real-world management plans. In all simulations, the minimum cost of a harvest $\left(c_{\text {min }}\right)$ was set to 10 , the manager budget to 10,000 , and the user budget was varied between 5000 and 10,000 (see Appendix 1, Fig. A1.1). Management effectiveness was assessed as the mean resource population growth at time step 10 across iterations. We then modeled management effectiveness as a function of decision-making bias and user compliance using generalized additive models (GAMs) with tensor product smooths ( $\mathrm{R}$ package $\mathrm{mgcv}$ ). We present our findings in the form of 2-dimensional contour surfaces.

As a control, we ensured that in the absence of disagreement among manager, user, and conservation objectives, the simulated resource population is managed effectively regardless of decisionmaking bias and user compliance levels. This was done by setting user, conservationist, and manager targets to 1000 resource units.

\section{Application to harvested species}

We compared predictions from our model against data on 206 terrestrial harvested species from the International Union for the Conservation of Nature's (IUCN) Red List of Threatened Species. We considered species belonging to the orders Anseriformes (geese and ducks, $N=37$ ), Cetartiodactyla (eventoed ungulates, $N=90$ ) and Carnivora (carnivores, $N=79$ ) because these are commonly targeted by subsistence, recreational, and trophy hunting activities globally (Di Minin et al. 2019, Hill et al. 2019).

Using the "advanced search" option on the IUCN Red List web site (https://www.iucnredlist.org/), we filtered species by criteria relating to Taxonomy ("Anseriformes," "Cetartiodactyla," and "Carnivora"), Red List Category ("NT or LR/nt" and "LC or LR/lc"), and Threats ("Intentional use (species is the target)"). We only considered species listed as Least Concern or Near Threatened so as to minimize confounding factors associated with threat status. Filtering resulted in a total of 206 species to which the classification of decision-making bias and user compliance shown in Appendix 4 (Fig. A4.1) was applied. More specifically, we classified each species according to (1) its stated population trend at the latest assessment (decreasing, stable, or increasing), (2) the type of harvesting it was most commonly under (unregulated, regulated, or banned), and (3) the level of illegal harvest most commonly reported for a population (low, medium, or high). We then used population trend as a measure of management outcome, harvesting type as a measure of decisionmaking bias (with unregulated and banned taken to reflect prouser and pro-conservation biases), and illegal harvest level as a measure of user compliance. Classifications were carried out by two of the authors and subsequently compared to ensure consistency.

We derived the proportion of species showing a decreasing, stable, and increasing population trend for each of the different combinations of decision-making bias and user compliance. We 
also modeled population trend as a function of the interaction between decision-making bias and user compliance using a generalized additive model with Gaussian error structure and tensor product smooth. This resulted in an interpolated surface showing mean population trajectory (from -1 to 1) as a function of decision-making bias and user compliance classifications.

\section{RESULTS}

\section{Model predictions}

When simulated manager, user, and conservation objectives were identical, reflecting perfect agreement on target abundance for the harvested resource, mean population growth remained stable and on target over the course of 10 management years (Fig. 2). This parameterization is important because it verifies that the genetic algorithm is operating as intended by producing expected results of optimal (or near-optimal) harvest decisions over both short and long time frames. It also reflects a null model of effective management in the absence of conflicting stakeholder objectives, against which the effect of lobbying and illegal harvesting can be compared.

Fig. 2. Mean population growth over a 10-year management period as a function of decision-making bias and user compliance when manager, users, and conservationists agree on the management target. Decision-making bias ranges from entirely pro-user (-1, harvest is always unregulated) to proconservation $(+1$, harvest is always banned), with 0 representing a scenario in which manager quota decisions cannot be lobbied. When user compliance is 0 , users will always partake in illegal harvesting while a value of 1 ensures users will fully comply with the quota put forward by the manager (postlobbying). Each point represents the mean population growth across 100 iterations. The surface represents predictions from a generalized additive model with decision-making bias and user compliance specified as tensor product smooths. Overall, the management target of maintaining a stable population trend is achieved for all combinations of decisionmaking bias and user compliance.

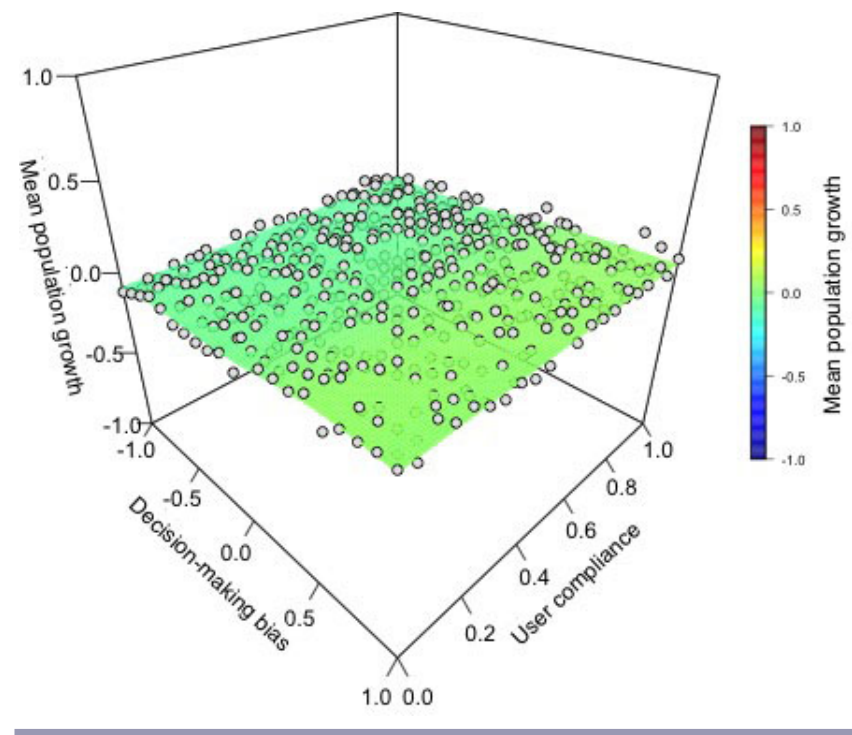

In the presence of conflicting stakeholder objectives, we find that management outcome is shaped by the interaction between decision-making bias and user compliance levels (Fig. 3). We make five predictions from our model. First, when lobbying has no effect on management decisions, a stable resource abundance is only achieved at high levels of user compliance (Fig. 3; $I=0$ and $E=1$ ). Second, as compliance decreases from high to moderate levels, i.e., increasing illegal harvest, stable and increasing resource population trends are possible to maintain if decision making by the manager is biased toward conservation objectives (Fig. $3 ; I>0$ and $E>0.5$ ). Third, the combination of bias toward conservation objectives and low user compliance leads to both an increased risk of negative population growth rates and an increased probability of extinction (Fig. $3 ; I>0$ and $E<0.5$ ). This arises because such decision making leads to a higher likelihood of harvesting being banned and consequently higher resource abundance, to which users respond by increasing illegal harvesting pressure when compliance is low. Fourth, as user compliance tends toward minimum levels, negative growth rates occur regardless of bias in decision making, although they are less severe if decision making is unaffected by lobbying (Fig. 3; cases when $E<0.5$ ). Last, when management decisions are biased toward user interests, population abundance declines over the course of the management period (Fig. 3; cases when $I<0$ ). In this case, compliance has little effect because lobbying already satisfies user interests. Importantly, these predicted patterns of management outcome were not sensitive to choice of resource population growth rate (Appendix 5, Fig. A5.1).

\section{Application to harvested species}

Of the 206 species considered, $26(12.6 \%)$ showed an increasing population trend, while $61(29.6 \%)$ and $119(57.8 \%)$ exhibited stable and decreasing trends, respectively. The proportion of species showing a stable population trend was highest when user compliance was high (Fig. 4a-c, Appendix 6, Table A6.1), and particularly when harvest was regulated ( $47 \%$ stable trends), a finding that is consistent with our model results (Fig. 3). Species showing increasing population trends were most strongly associated with high compliance ( 23 out of 26 species), and either regulated (16 out of 23 species) or banned (5 out of 23 species) harvesting. Eighty-one percent of the species classified under regulated harvest and high compliance showed stable or increasing population trends.

In contrast, species populations were overwhelmingly decreasing when compliance with harvesting rules was low, regardless of decision-making bias (Fig. 4g-i). This mirrors the dominant effect of changes in illegal harvesting over lobbying in driving resource mismanagement, which our model also predicts. As user compliance decreased from high to low, however, species were more likely to exhibit stable and increasing population trends when harvest was characterized as regulated rather than unregulated or banned. Overall, predictions from our theoretical model were strongly correlated with those obtained from empirical data (Pearson's correlation corrected for autocorrelation: = $0.897, \mathrm{P}<0.05$ for a simulated intrinsic growth rate of $r_{\max }=$ $0.1 ;=0.853, \mathrm{P}<0.05$ for $r_{\text {max }}=0.2$; and $=0.821, \mathrm{P}<0.05$ for $r_{\text {max }}$ $=0.3$, respectively; Appendix 7, Fig. A7.1). 
Fig. 3. Mean population growth (a) and extinction probability (b) over a 10-year management period as a function of management decision-making bias and user compliance with harvesting rules. Panels in (c) relate to different areas of the model prediction surfaces, and illustrate time series of resource abundance, original quota put forward by the manager, modified quota as a result of lobbying, and final harvest including legal and illegal off takes for different combinations of decision-making bias and user compliance. Decision-making bias ranges from entirely pro-user (-1, harvest is always unregulated) to pro-conservation $(+1$, harvest is always banned), with 0 representing a scenario in which manager quota decisions cannot be lobbied (red dashed line). When user compliance is 0 , users will always partake in illegal harvesting, while a value of 1 ensures users will fully comply with the quota put forward by the manager (postlobbying). The 2D contour surfaces were obtained from generalized additive models with decisionmaking bias and user compliance specified as tensor product smooths. Results are shown for a simulation in which the intrinsic growth rate of the harvested population was 0.2 and the carrying capacity was 2000 individuals.

a)

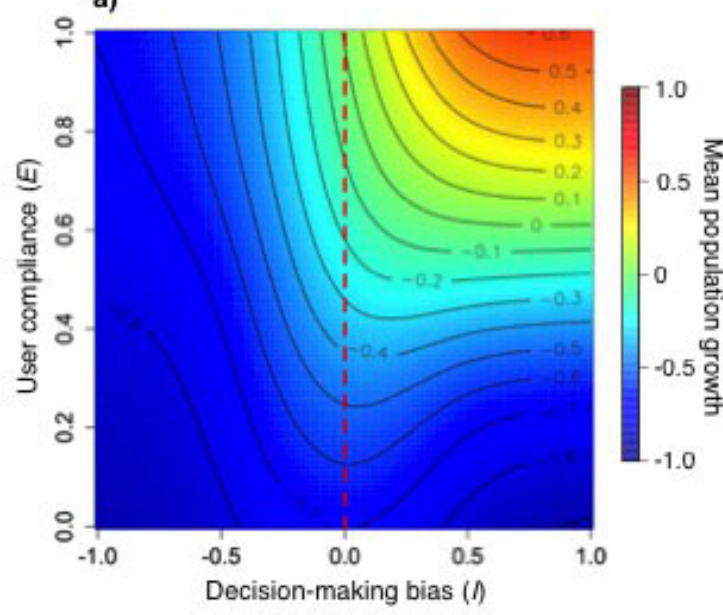

b)

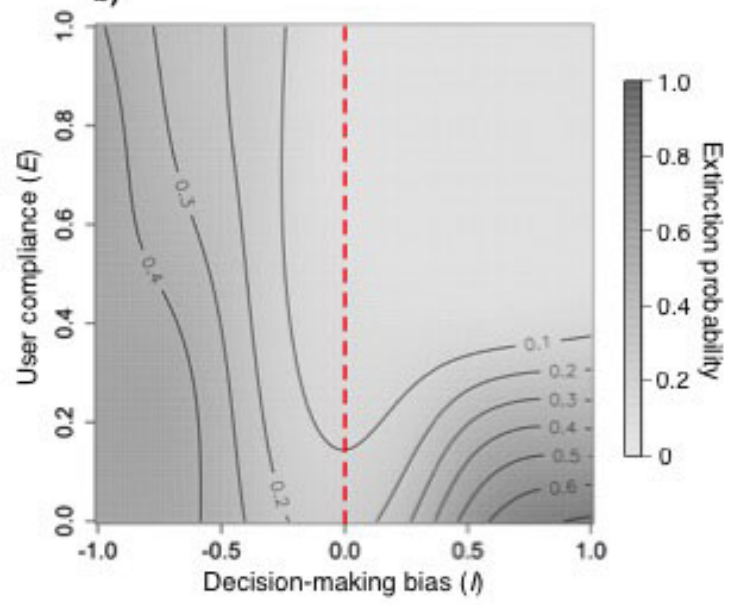

c)
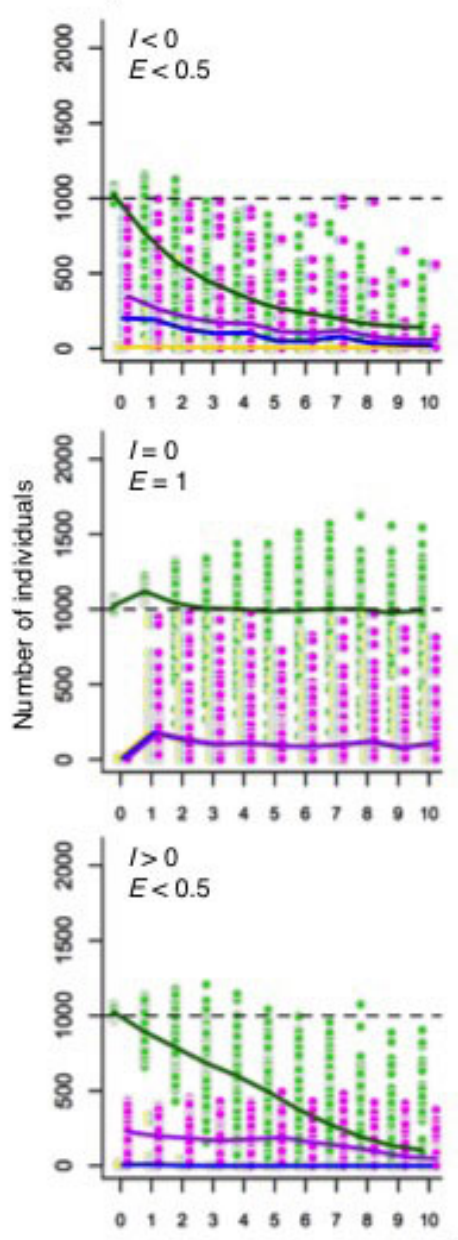

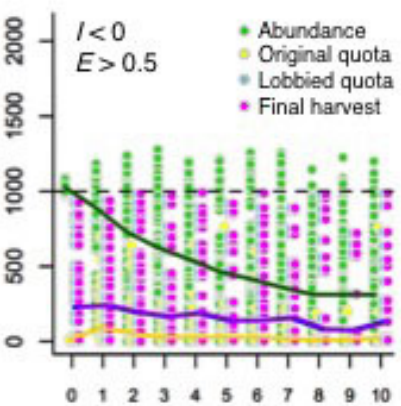

$8+1>0$

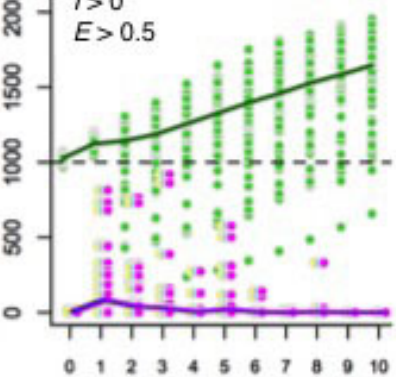

\&े $f=0$
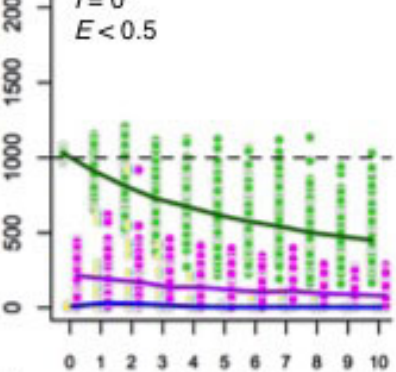

Time step

\section{DISCUSSION}

\section{Modeling dynamic governance processes}

Our work provides a holistic and versatile resource management framework that accounts for dynamic governance processes such as conflict, lobbying, and rule compliance. It highlights the complex interaction between lobbying and compliance in the presence of conflicts, and its substantial influence on the sustainability of natural resource use. Most notably, we find that lobbying for management decisions that favor conservation interests can offset medium levels of user noncompliance. Yet this comes at a risk of increased sensitivity to further reductions in user compliance, which results in higher probabilities of resource extinction relative to scenarios in which management decision making is unbiased. These theoretical predictions are well supported in real-world systems. Indeed, there is increasing evidence in the scientific literature that outright harvest bans can lead to increased levels of illegal harvest (Di Minin et al. 2016, Raithel et al. 2017). For example, bans on trophy hunting imports and activities without provision of viable land-use alternatives can lead to a rise in unregulated killing of wildlife (Lindsey et al. 2017, Dickman et al. 2019).

We also demonstrate the critical effect of changes in user compliance on sustainable resource use. Both our theoretical modeling and empirical analysis show that, when management 
Fig. 4. Proportion of harvested IUCN Red List species with declining, stable, or increasing population trends for different combinations of decision-making bias and user compliance (panels a-i). $\mathrm{N}$ indicates the sample size for each combination. The 2D contour surface represents the interpolated mean population trend across harvested species $(-1=$ decreasing, $0=$ stable, $1=$ increasing) for varying levels of decision-making bias and user compliance, and was obtained from a generalized additive model with decision-making bias and user compliance specified as tensor product smooths. The location of letters placed on the prediction surface relate to data shown in panels (a) to (i).
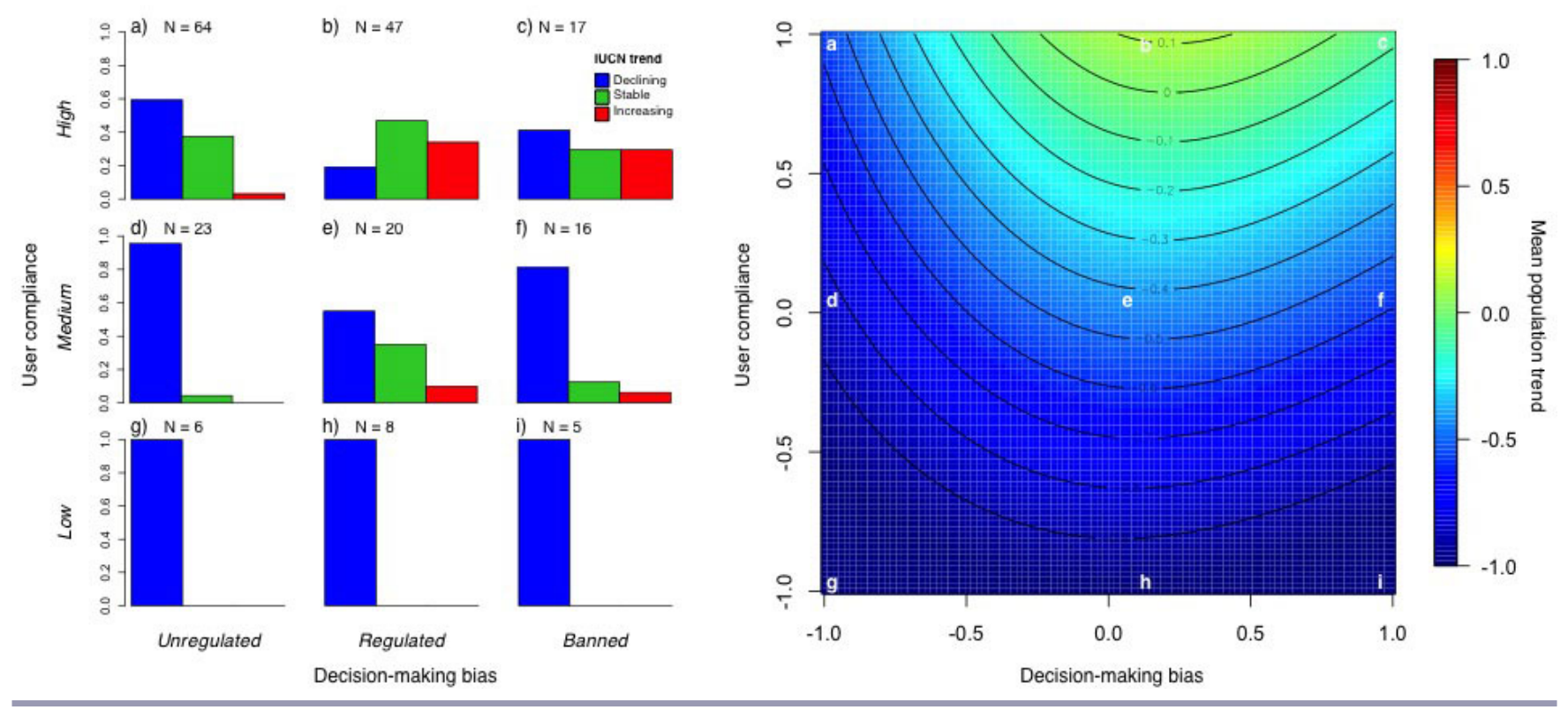

decisions are unbiased, stable resource trends are most likely to be achieved when compliance is high. This finding may seem obvious, but broad consensus between conceptual models and empirical approaches that encompass a range of species and incorporate the link with lobbying has been lacking (Travers et al. 2019b). The pattern we observe arises because user actions have a direct effect on the resource population, whereas lobbying targets decision making by the manager. In other words, users have the "final say" on what harvest will be implemented in a given time step (Eriksen et al. 2018, Shirley and Gore 2019), thus emphasizing their potential power to drive resource populations trends. Increasing user compliance with harvesting rules should therefore be a priority when seeking to sustainably manage natural resource use. This could be achieved through increased enforcement or by reducing demand (Holden et al. 2019) and implementing bottom-up approaches to management (Duffy et al. 2016, Cooney et al. 2017), such as the development of comanagement plans that bring together all parties in search of an agreement on management targets prior to actions being carried out (Armitage et al. 2009, Young et al. 2016, Redpath et al. 2017). Our model parameterization in which all parties agree on a population target demonstrates the value of compromise in achieving sustainable natural resource use.

\section{Application to real-world harvesting systems}

Our theoretical predictions provided a strong quantitative match to those obtained from our analysis of IUCN red list data, thus demonstrating the broad applicability of our approach. Yet the importance of considering the interaction between decisionmaking bias and user compliance can also be emphasized through a more qualitative assessment of real-world case studies. Many ungulate and carnivore species are killed illegally in response to crop damage or livestock depredation, respectively, leading to declining populations despite high levels of international and national protection (Soofi et al. 2019). For example, Suutarinen and Kojola (2017) show how the illegal hunting of protected grey wolves (Canis lupus) in Finland increases with population size and strongly regulates population trends, despite the existence of "exceptional permits" to hunt wolves that cause damage to livestock. Here, strong protection laws that have enabled the wolf population to grow may have also influenced rates of illegal harvesting. In this case, our model could help highlight the damaging effect of conflict on sustainable management, and adjust legal harvest quotas based on quantified or expected rates of illegal harvesting, i.e., compliance.

Similarly, many species of herbivorous waterfowl in Europe and North America have experienced exponential increases in population size partly because of pro-conservation, protective legislation and high user compliance, yet this trend has started to occur at the detriment of agricultural crop production on which these species have become reliant (Lefebvre et al. 2017, Cusack et al. 2019). On the island of Islay in Scotland, legal harvesting of the wintering Greenland Barnacle Goose (Branta leucopsis) population, a species protected under EU law, has now been enforced because of lobbying pressure from agricultural interest groups, whose livelihoods are affected by goose grazing and damage to livestock pastures (McKenzie and Shaw 2017). However, the lack of evidence-based decision making relating to hunting quotas has been criticized by conservation organizations, 
which have brought forth lawsuits in an attempt to minimize culling. Although recent work has been used to derive more sustainable harvesting quotas based on the GMSE approach (Bunnefeld et al. 2020), it remains unclear how lobbying by both conservation and agricultural interests will affect manager decision making. Our approach could contribute to evidencebased decision making to minimize the risk of conflict escalation and dangerous tipping points in goose population trends due to overharvesting.

The relevance of our model goes beyond the orders considered in our IUCN analysis. The management of populations of birds of prey, for example, is also prone to conflict and governance issues. In the UK, the Hen Harrier (Circus cyaneus) is of high conservation concern and, although strictly protected, its population continues to be heavily impacted by illegal killing (Ludwig et al. 2017). Hen Harriers prey on Red Grouse (Lagopus lagopus scotica), a species whose populations and moorland habitat are intensively managed for shooting. The protection of the Hen Harrier is viewed as a threat to the Red Grouse shooting industry, resulting in widespread illegal killing of the raptor species on grouse moors (Murgatroyd et al. 2019). Here, our model could help explore how a healthy Hen Harrier population could be achieved despite conflicting stakeholder population targets, low compliance, and strong conservation pressure to ban legal harvesting (Redpath and Thirgood 2009).

\section{Model assumptions and limitations}

Our approach aims to portray the functioning of complex and dynamic harvesting systems often characterized by high levels of uncertainty (Bunnefeld et al. 2011). In doing so, we have made a number of assumptions about the ecological and social components of these systems. In a first instance, we have implemented a simple logistic population growth model to define the general trajectory of resource abundance. Such a model provides a heuristic platform on which to evaluate population trends whilst minimizing biological complexity (Milner-Gulland 2011). We stress that the GMSE approach used in this study also enables the application of more elaborate resource growth models (see Duthie et al. 2018), which may be better suited to particular case studies, such as a population of a species in a given area, or be parameterized to include more or less demographic and environmental stochasticity (Fryxell et al. 2010, Milner-Gulland 2011). Like the assumption of perfect observation, an unlikely characterization of real-world systems, the simplicity of our population model allows us to isolate the effect of governance processes above and beyond structural and measurement uncertainties (Bunnefeld et al. 2011).

Our approach employs a genetic algorithm to optimize goaloriented quota decision making, which provides a more rapid alternative to a trial and error method whereby a range of quota levels are tested sequentially (Duthie et al. 2018). Although the resulting quotas are derived with a level of variation that is realistic of management decisions, this variation remains random and we do not explicitly model the mechanisms driving decision making for a given manager, e.g., inherent biases. Similarly, subsequent lobbying actions, i.e., external pressures, affect the decision provided by the genetic algorithm, but not the simulated selection process itself. Even though our goal-oriented decision makers in the model do not reflect the entire complexity of people in the real world, our approach represents an important step forward compared to error-free and static decisions used in more standard harvesting models (Dobson et al. 2019).

Despite their evident potential for influencing sustainable use, reliable measures of decision-making bias and its relationship with lobbying pressure, as well as of user compliance, are sorely lacking for most harvested species. For instance, the link between social norms and illegal behavior has received little attention in the literature (Nyborg et al. 2016). Although the simulations presented here assume both lobbying pressure and illegal harvesting increase exponentially as resource abundance deviates from a stakeholder's goal, these functions should be modified and parameterized based on available real-world data or more detailed qualitative assessments of social norms and values. Last, our approach makes the key assumption that resource user behavior is driven by a desire to maximize harvest in the short term given a resource abundance goal, i.e., economic gain. Although this extreme is used to illustrate the breadth of our approach, we acknowledge that many factors, such as cultural norms and traditions, can promote self-sustaining harvesting systems (Ostrom 2009, Struebig et al. 2018). We note that, as a start, our approach can accommodate social norms by allowing the goal of resource users to be greater than population extinction, indicating a desire to maintain abundance in the long term.

\section{CONCLUSION}

Although MSE models are often tailored to specific case studies, our analysis reveals general patterns across theoretical and empirical analyses. Specifically, although lower compliance may be offset by increased decision bias toward conservation goals, extinction risk increases when high levels of such bias are combined with low user compliance. In addition, management decisions free from any influence of lobbying can only successfully achieve sustainable harvesting given low levels of illegal harvesting and thus buy-in from stakeholders. Given this balancing act, there is an urgent need for management approaches that address the underlying social conflicts over the sustainable use of biodiversity. Such approaches should seek where possible to promote consensus between stakeholders on population targets, for instance by investing in detailed assessments of the views and needs of each interest group, and their overlap. In cases where consensus proves challenging to achieve, our modeling approach could help simulate and predict how the resulting governance processes through which divergence is expressed could affect the sustainability of harvested populations. In turn, this would allow management decisions to anticipate the effects of potential lobbying and noncompliance. Importantly, use of the proposed approach need not be restricted to natural resource management. Indeed, individual responses (including compliance) to conflict, policy, and lobbying are of high relevance to issues such as climate change mitigation (Chakra et al. 2018) and sustainable wildlife trade (Nuno et al. 2018), in which the power of consumers (of carbon and wildlife, respectively) is likely to be high.

Responses to this article can be read online at: http://www.ecologyandsociety.org/issues/responses. php/11552 


\section{Acknowledgments:}

This study received funding from the European Research Council under the European Union's H2020/ERC grant agreement no. 679651 (ConFooBio) to N.B. A.B.D. is supported by a Leverhulme Trust Early Career Fellowship. We are grateful to Tim Coulson and E.J. Milner-Gulland for comments on previous versions of this manuscript. All authors conceived the study, developed the underlying theory and software, discussed the results, and wrote the manuscript. J.J.C. carried out the simulations and analyzed the data.

\section{Data Availability Statement:}

The data and code are available in the manuscript supporting information.

\section{LITERATURE CITED}

Adams, W. M. 2017. Sleeping with the enemy? Biodiversity conservation, corporations and the green economy. Journal of Political Ecology 24:243-257. https://doi.org/10.2458/v24i1.20804

Andrén, H., N. T. Hobbs, M. Aronsson, H. Brøseth, G. Chapron, J. D. Linnell, J. Odden, J. Persson, and E. B. Nilsen. 2020. Harvest models of small populations of a large carnivore using Bayesian forecasting. Ecological Applications 30(3):e02063. https://doi. org/10.1002/eap.2063

Armitage, D. R., D. K. Okamoto, J. J. Silver, T. B. Francis, P. S. Levin, A. E. Punt, I. P. Davies, J. S. Cleary, S. C. Dressel, R. R. Jones, H. Kitka, L. C. Lee, A. D. MacCall, J. A. McIsaac, M. R. Poe, S. Reifenstuhl, A. O. Shelton, J. O. Schmidt, T. F. Thornton, R. Voss, and J. Woodruff. 2019. Integrating governance and quantitative evaluation of resource management strategies to improve social and ecological outcomes. BioScience 69:523-532. https://doi.org/10.1093/biosci/biz059

Armitage, D. R., R. Plummer, F. Berkes, R. I. Arthur, A. T. Charles, I. J. Davidson-Hunt, A. P. Diduck, N. C. Doubleday, D. S. Johnson, M. Marschke, P. McConney, E. W. Pinkerton, and E. K. Wollenberg. 2009. Adaptive co-management for socialecological complexity. Frontiers in Ecology \& the Environment 7:95-102. https://doi.org/10.1890/070089

Aryal, A., C. G. Morley, and I. G. McLean. 2018. Conserving elephants depend on a total ban of ivory trade globally. Biodiversity and Conservation 27:2767-2775. https://doi. org/10.1007/s10531-018-1534-X

Audzijonyte, A., H. Pethybridge, J. Porobic, R. Gorton, I. Kaplan, and E. A. Fulton. 2019. Atlantis: a spatially explicit end-to-end marine ecosystem model with dynamically integrated physics, ecology and socio-economic modules. Methods in Ecology and Evolution 10:1814-1819. https://doi.org/10.1111/2041-210X.13272

Baumgartner, F. R., J. M. Berry, M. Hojnacki, B. L. Leech, and D. C. Kimball. 2009. Lobbying and policy change: who wins, who loses, and why. University of Chicago Press, Chicago, Illinois, USA. https://doi.org/10.7208/chicago/9780226039466.001.0001

Baynham-Herd, Z., S. Redpath, N. Bunnefeld, T. Molony, and A. Keane. 2018. Conservation conflicts: behavioural threats, frames, and intervention recommendations. Biological Conservation 222:180-188. https://doi.org/10.1016/j.biocon.2018.04.012

Benítez-López, A., R. Alkemade, A. M. Schipper, D. J. Ingram, P. A. Verweij, J. A. J. Eikelboom, and M. A. J. Huijbregts. 2017. The impact of hunting on tropical mammal and bird populations. Science 356:180-183. https://doi.org/10.1126/science.aaj1891

Bevir, M. 2012. Governance: a very short introduction. Oxford University Press, Oxford, UK. https://doi.org/10.1093/ actrade/9780199606412.001.0001

Biggs, D., F. Courchamp, R. Martin, and H. P. Possingham. 2013. Legal trade of Africa's rhino horns. Science 339:1038-1039. https://doi.org/10.1126/science.1229998

Blanchard, J. L., K. H. Andersen, F. Scott, N. T. Hintzen, G. Piet, and S. Jennings. 2014. Evaluating targets and trade-offs among fisheries and conservation objectives using a multispecies size spectrum model. Journal of Applied Ecology 51:612-622. https:// doi.org/10.1111/1365-2664.12238

Bodin, Ö. 2017. Collaborative environmental governance: achieving collective action in social-ecological systems. Science 357:eaan1114. https://doi.org/10.1126/science.aan1114

Bunnefeld, N., E. Hoshino, and E. J. Milner-Gulland. 2011. Management strategy evaluation: a powerful tool for conservation? Trends in Ecology \& Evolution 26:441-447. https:// doi.org/10.1016/j.tree.2011.05.003

Bunnefeld, N., and E. J. Milner-Gulland. 2016. Opportunities and pitfalls in realising the potential contribution of trophy hunting to antelope conservation. Pages 92-107 in J. Bro-Jørgensen and D. P. Mallon, editors. Antelope conservation: from diagnosis to action. Wiley-Blackwell, Hoboken, New Jersey, USA. https://doi. org/10.1002/9781118409572.ch6

Bunnefeld, N., E. Nicholson, and E. J. Milner-Gulland, editors. 2017. Decision-making in conservation and natural resource management: models for interdisciplinary approaches. Cambridge University Press, Cambridge, UK. https://doi.org/10.1017/9781316135938

Bunnefeld, N., R. A. Pozo, J. J. Cusack, A. B. Duthie, and J. Minderman. 2020. Development of a population model tool to predict shooting levels of Greenland Barnacle Geese on Islay. SNHR Report No. 1039. Scottish Natural Heritage Research Report, Inverness, UK.

Ceballos, G., P. R. Ehrlich, and R. Dirzo. 2017. Biological annihilation via the ongoing sixth mass extinction signaled by vertebrate population losses and declines. Proceedings of the National Academy of Sciences 114:E6089-E6096. https://doi. org/10.1073/pnas.1704949114

Chakra, M. A., S. Bumann, H. Schenk, A. Oschlies, and A. Traulsen. 2018. Immediate action is the best strategy when facing uncertain climate change. Nature Communications 9:2566. https:// doi.org/10.1038/s41467-018-04968-1

Challender, D. W. S., and D. C. MacMillan. 2019. Investigating the influence of non-state actors on amendments to the CITES appendices. Journal of International Wildlife Law \& Policy 22:90-114. https://doi.org/10.1080/13880292.2019.1638549 
Chen, Y., H. Liu, and J. Heinen. 2019. Challenges in the conservation of an over-harvested plant species with high socioeconomic values. Sustainability 11(15):4194. https://doi. org/10.3390/su11154194

Cooney, R., D. Roe, H. Dublin, J. Phelps, D. Wilkie, A. Keane, H. Travers, D. Skinner, D. W. S. Challender, J. R. Allan, and D. Biggs. 2017. From poachers to protectors: engaging local communities in solutions to illegal wildlife trade. Conservation Letters 10:367-374. https://doi.org/10.1111/conl.12294

Cox, M., S. Villamayor-Tomas, G. Epstein, L. Evans, N. C. Ban, F. Fleischman, M. Nenadovic, and G. Garcia-Lopez. 2016. Synthesizing theories of natural resource management and governance. Global Environmental Change 39:45-56. https://doi. org/10.1016/j.gloenvcha.2016.04.011

Cumming, G. S. 2018. A review of social dilemmas and socialecological traps in conservation and natural resource management. Conservation Letters 11:e12376. https://doi. org/10.1111/conl.12376

Cusack, J. J., A. B. Duthie, O. S. Rakotonarivo, R. A. Pozo, T. H. Mason, J. Månsson, L. Nilsson, I. M. Tombre, E. Eythórsson, J. Madsen, A. Tulloch, R. D. Hearn, S. Redpath, and N. Bunnefeld. 2019. Time series analysis reveals synchrony and asynchrony between conflict management effort and increasing large grazing bird populations in northern Europe. Conservation Letters 12: e12450. https://doi.org/10.1111/conl.12450

Di Minin, E., T. M. Brooks, T. Toivonen, S. H. M. Butchart, V. Heikinheimo, J. E. M. Watson, N. D. Burgess, D. W. S. Challender, B. Goettsch, R. Jenkins, and A. Moilanen. 2019. Identifying global centers of unsustainable commercial harvesting of species. Science Advances 5:eaau2879. https://doi.org/10.1126/sciadv. $\underline{\text { aau2879 }}$

Di Minin, E., N. Leader-Williams, and C. J. A. Bradshaw. 2016. Banning trophy hunting will exacerbate biodiversity loss. Trends in Ecology \& Evolution 31:99-102. https://doi.org/10.1016/j. tree.2015.12.006

Díaz, S., J. Settele, E. S. Brondízio, H. T. Ngo, M. Guèze, J. Agard, A. Arneth, P. Balvanera, K. A. Brauman, S. H. M. Butchart, K. M. A. Chan, L. A. Garibaldi, K. Ichii, J. Liu, S. M. Subrmanian, G. F. Midgley, P. Miloslavich, Z. Molnár, D. Obura, A. Pfaff, S. Polasky, A. Purvis, J. Razzaque, B. Reyers, R. R. Chowdhury, Y.J. Shin, I. Visseren-Hamakers, K. J. Wilis, and C. N. Zayas. 2019. Summary for policymakers of the global assessment report on biodiversity and ecosystem services. Intergovernmental SciencePolicy Platform on Biodiversity and Ecosystem Services. 7th session of the IPBES Plenary. IPBES Secretariat, Bonn, Germany. https://doi.org/10.5281/zenodo.3553579

Dickman, A., R. Cooney, P. J. Johnson, M. P Louis, D. Roe, and 128 signatories. 2019. Trophy hunting bans imperil biodiversity. Science 365:874. https://doi.org/10.1126/science.aaz0735

Dobson, A. D. M., E. de Lange, A. Keane, H. Ibbett, and E. J. Milner-Gulland. 2019. Integrating models of human behaviour between the individual and population levels to inform conservation interventions. Philosophical Transactions of the Royal Society B: Biological Sciences 374:20180053. https://doi. org/10.1098/rstb.2018.0053
Duffy, R., F. A. V. St John, B. Büscher, and D. Brockington. 2016. Toward a new understanding of the links between poverty and illegal wildlife hunting. Conservation Biology 30:14-22. https:// doi.org/10.1111/cobi.12622

Duthie, A. B., J. J. Cusack, I. J. Jones, J. Minderman, E. B. Nilsen, R. A. Pozo, O. S. Rakotonarivo, B. Van Moorter, and N. Bunnefeld. 2018. GMSE: an R package for generalised management strategy evaluation. Methods in Ecology and Evolution 9:2396-2401. https://doi.org/10.1111/2041-210X.13091

Eriksen, L. F., P. F. Moa, and E. B. Nilsen. 2018. Quantifying risk of overharvest when implementation is uncertain. Journal of Applied Ecology 55:482-493. https://doi.org/10.1111/1365-2664.12992

Folke, C., S. R. Carpenter, B. Walker, M. Scheffer, T. Chapin, and J. Rockström. 2010. Resilience thinking: integrating resilience, adaptability and transformability. Ecology and Society 15(4):20. https://doi.org/10.5751/ES-03610-150420

Fryxell, J. M., C. Packer, K. McCann, E. J. Solberg, and B. E. Sæther. 2010. Resource management cycles and the sustainability of harvested wildlife populations. Science 328:903-906. https:// doi.org/10.1126/science. 1185802

Gamelon, M., B. K. Sandercock, and B. E. Sæther. 2019. Does harvesting amplify environmentally induced population fluctuations over time in marine and terrestrial species? Journal of Applied Ecology 56:2186-2194. https://doi.org/10.1111/1365-$\underline{2664.13466}$

Gavin, M. C., J. N. Solomon, and S. G. Blank. 2010. Measuring and monitoring illegal use of natural resources. Conservation Biology 24:89-100. https://doi.org/10.1111/j.1523-1739.2009.01387. $\underline{\mathrm{x}}$

Harford, W. J., T. Gedamke, E. A. Babcock, R. Carcamo, G. McDonald, and J. R. Wilson. 2016. Management strategy evaluation of a multi-indicator adaptive framework for datalimited fisheries management. Bulletin of Marine Science 92:423-445. https://doi.org/10.5343/bms.2016.1025

Hill, J. E., T. L. DeVault, and J. L. Belant. 2019. Cause-specific mortality of the world's terrestrial vertebrates. Global Ecology and Biogeography 28:680-689. https://doi.org/10.1111/geb.12881

Holden, M. H., D. Biggs, H. Brink, P. Bal, J. Rhodes, and E. McDonald-Madden. 2019. Increase anti-poaching lawenforcement or reduce demand for wildlife products? A framework to guide strategic conservation investments. Conservation Letters 12:e12618. https://doi.org/10.1111/conl.12618

Keane, A., J. P. G. Jones, G. Edwards-Jones, and E. J. MilnerGulland. 2008. The sleeping policeman: understanding issues of enforcement and compliance in conservation. Animal Conservation 11:75-82. https://doi.org/10.1111/j.1469-1795.2008.00170. $\underline{\mathrm{X}}$

Kolbe, J., K. Proffitt, J. Nowak, and H. Robinson. 2017. Population monitoring and modeling to enable an adaptive management strategy for mountain lions in Montana. Intermountain Journal of Sciences 23:76-76.

Kuparinen, A., and M. Festa-Bianchet. 2017. Harvest-induced evolution: insights from aquatic and terrestrial systems. 
Philosophical Transactions of the Royal Society B: Biological Sciences 372:20160036. https://doi.org/10.1098/rstb.2016.0036

Lefebvre, J., G. Gauthier, J.-F. Giroux, A. Reed, E. T. Reed, and L. Bélanger. 2017. The greater snow goose Anser caerulescens atlanticus: managing an overabundant population. Ambio 46:262-274. https://doi.org/10.1007/s13280-016-0887-1

Lindsey, P. A., L. S. Petracca, P. J. Funston, H. Bauer, A. Dickman, K. Everatt, M. Flyman, P. Henschel, A. E. Hinks, S. Kasiki, A. Loveridge, D. W. Macdonald, R. Mandisodza, W. Mgoola, S. M. Miller, S. Nazerali, L. Siege, K. Uiseb, and L. T. B. Hunter. 2017. The performance of African protected areas for lions and their prey. Biological Conservation 209:137-149. https://doi.org/10.1016/ j.biocon.2017.01.011

Lockwood, M., J. Davidson, A. Curtis, E. Stratford, and R. Griffith. 2010. Governance principles for natural resource management. Society and Natural Resources 23:986-1001. https:// doi.org/10.1080/08941920802178214

Loveridge, A. J., M. Valeix, G. Chapron, Z. Davidson, G. Mtare, and D. W. Macdonald. 2016. Conservation of large predator populations: demographic and spatial responses of African lions to the intensity of trophy hunting. Biological Conservation 204:247-254. https://doi.org/10.1016/j.biocon.2016.10.024

Ludwig, S. C., S. Roos, D. Bubb, and D. Baines. 2017. Long-term trends in abundance and breeding success of Red Grouse and Hen Harriers in relation to changing management of a Scottish grouse moor. Wildlife Biology. https://doi.org/10.2981/wlb.00246

Lute, M. L., and M. L. Gore. 2014. Knowledge and power in wildlife management. Journal of Wildlife Management 78:1060-1068. https://doi.org/10.1002/jwmg.754

Mace, G. M. 2014. Whose conservation? Science 345:1558-1560. https://doi.org/10.1126/science.1254704

McKenzie, R., and J. M. Shaw. 2017. Reconciling competing values placed upon goose populations: the evolution of and experiences from the Islay Sustainable Goose Management Strategy. Ambio 46:198-209. https://doi.org/10.1007/s13280-016-0880-8

Meng, K. C., and A. Rode. 2019. The social cost of lobbying over climate policy. Nature Climate Change 9:472-476. https://doi. org/10.1038/s41558-019-0489-6

Milner-Gulland, E. J. 2011. Integrating fisheries approaches and household utility models for improved resource management. Proceedings of the National Academy of Sciences 108:1741-1746. https://doi.org/10.1073/pnas.1010533108

Milner-Gulland, E. J. 2012. Interactions between human behaviour and ecological systems. Philosophical Transactions of the Royal Society B: Biological Sciences 367:270-278. https://doi. org/10.1098/rstb.2011.0175

Milner-Gulland, E. J., and K. Shea. 2017. Embracing uncertainty in applied ecology. Journal of Applied Ecology 54:2063-2068. https://doi.org/10.1111/1365-2664.12887

Moa, P. F., L. F. Eriksen, and E. B. Nilsen. 2017. Harvest regulations and implementation uncertainty in small game Harvest management. Frontiers in Ecology and Evolution 5:118. https://doi.org/10.3389/fevo.2017.00118
Müller-Hansen, F., M. Schlüter, M. Mäs, J. F. Donges, J. J. Kolb, K. Thonicke, and J. Heitzig. 2017. Towards representing human behavior and decision making in Earth system models-an overview of techniques and approaches. Earth System Dynamics 8:977-1007. https://doi.org/10.5194/esd-8-977-2017

Murgatroyd, M., S. M. Redpath, S. G. Murphy, D. J. T. Douglas, R. Saunders, and A. Amar. 2019. Patterns of satellite tagged Hen Harrier disappearances suggest widespread illegal killing on British grouse moors. Nature Communications 10:1094. https:// doi.org/10.1038/s41467-019-09044-w

Murray, M. 2003. Overkill and sustainable use. Science 299:1851-1853. https://doi.org/10.1126/science.1079823

Nuno, A., J. M. Blumenthal, T. J. Austin, J. Bothwell, G. EbanksPetrie, B. J. Godley, and A. C. Broderick. 2018. Understanding implications of consumer behavior for wildlife farming and sustainable wildlife trade. Conservation Biology 32:390-400. https://doi.org/10.1111/cobi.12998

Nyborg, K., J. M. Anderies, A. Dannenberg, T. Lindahl, C. Schill, M. Schlüter, W. Neil Adger, K. J. Arrow, S. Barrett, S. Carpenter, F. S. Chapin III, A.-S. Crépin, G. Daily, P. Ehrlich, C. Folke, W. Jager, N. Kautsky, S. A. Levin, O. J. Madsen, S. Polasky, M. Scheffer, B. Walker, E. U. Weber, J. Wilen, A. Xepapadeas, and A. de Zeeuw. 2016. Social norms as solutions. Science 354:42-43. https://doi.org/10.1126/science.aaf8317

Orach, K., and M. Schlüter. 2016. Uncovering the political dimension of social-ecological systems: contributions from policy process frameworks. Global Environmental Change 40:13-25. https://doi.org/10.1016/j.gloenvcha.2016.06.002

Ostrom, E. 2009. A general framework for analyzing sustainability of social-ecological systems. Science 325:419-422. https://doi.org/10.1126/science.1172133

Punt, A. E., D. S. Butterworth, C. L. de Moor, J. A. A. De Oliveira, and M. Haddon. 2016. Management strategy evaluation: best practices. Fish and Fisheries 17:303-334. https://doi.org/10.1111/ faf.12104

Raithel, J. D., M. J. Reynolds-Hogland, D. N. Koons, P. C. Carr, and L. M. Aubry. 2017. Recreational harvest and incidentresponse management reduce human-carnivore conflicts in an anthropogenic landscape. Journal of Applied Ecology 54:1552-1562. https://doi.org/10.1111/1365-2664.12830

Redpath, S., and S. Thirgood. 2009. Hen Harriers and Red Grouse: moving towards consensus? Journal of Applied Ecology 46:961-963. https://doi.org/10.1111/j.1365-2664.2009.01702.x

Redpath, S. M., J. D. C. Linnell, M. Festa-Bianchet, L. Boitani, N. Bunnefeld, A. Dickman, R. J. Gutiérrez, R. J. Irvine, M. Johansson, A. Majić, B. J. McMahon, S. Pooley, C. Sandström, A. Sjölander-Lindqvist, K. Skogen, J. E. Swenson, A. Trouwborst, J. Young, and E. J. Milner-Gulland. 2017. Don't forget to look down-collaborative approaches to predator conservation. Biological Reviews 92:2157-2163. https://doi. org/10.1111/brv.12326

Redpath, S. M., J. Young, A. Evely, W. M. Adams, W. J. Sutherland, A. Whitehouse, A. Amar, R. A. Lambert, J. D. C. Linnell, A. Watt, and R. J. Gutiérrez. 2013. Understanding and 
managing conservation conflicts. Trends in Ecology \& Evolution 28:100-109. https://doi.org/10.1016/j.tree.2012.08.021

Ripple, W. J., C. Wolf, T. M. Newsome, M. G. Betts, G. Ceballos, F. Courchamp, M. W. Hayward, B. Van Valkenburgh, A. D. Wallach, and B. Worm. 2019. Are we eating the world's megafauna to extinction? Conservation Letters 12:e12627. https://doi. org/10.1111/conl.12627

Sandbrook, C. 2017. Weak yet strong: the uneven power relations of conservation. Oryx 51:379-380. https://doi.org/10.1017/ $\underline{\mathrm{S} 0030605317000618}$

Sanderson, E. W. 2006. How many animals do we want to save? The many ways of setting population target levels for conservation. BioScience 56:911-922. https://doi.org/10.1641/0006-3568 (2006)56[911:HMADWW]2.0.CO;2

Sayles, J. S., M. Mancilla Garcia, M. Hamilton, S. M. Alexander, J. A. Baggio, A. P. Fischer, K. Ingold, G. R. Meredith, and J. Pittman. 2019. Social-ecological network analysis for sustainability sciences: a systematic review and innovative research agenda for the future. Environmental Research Letters 14:9. https://doi.org/10.1088/1748-9326/ab2619

Schlüter, M., L. J. Haider, S. J. Lade, E. Lindkvist, R. Martin, K. Orach, N. Wijermans, and C. Folke. 2019b. Capturing emergent phenomena in social-ecological systems: an analytical framework. Ecology and Society 24(3):11. https://doi. org/10.5751/es-11012-240311

Schlüter, M., B. Müller, and K. Frank. 2019a. The potential of models and modeling for social-ecological systems research: the reference frame ModSES. Ecology and Society 24(1):31. https:// doi.org/10.5751/es-10716-240131

Schmolke, A., P. Thorbek, D. L. DeAngelis, and V. Grimm. 2010. Ecological models supporting environmental decision making: a strategy for the future. Trends in Ecology \& Evolution 25:479-486. https://doi.org/10.1016/j.tree.2010.05.001

Serrouya, R., B. N. McLellan, S. Boutin, D. R. Seip, and S. E. Nielsen. 2011. Developing a population target for an overabundant ungulate for ecosystem restoration. Journal of Applied Ecology 48:935-942. https://doi.org/10.1111/

j.1365-2664.2011.01998.x

Shea, K., and the NCEAS Working Group on Population Management. 1998. Management of populations in conservation, harvesting and control. Trends in Ecology \& Evolution 13:371-375. https://doi.org/10.1016/S0169-5347(98)01381-0

Shirley, E. A., and M. L. Gore. 2019. Trust in scientists and rates of noncompliance with a fisheries rule in the Brazilian Pantanal. PLoS ONE 14:e0207973. https://doi.org/10.1371/journal. pone. 0207973

Sibly, R. M., and J. Hone. 2002. Population growth rate and its determinants: an overview. Philosophical Transactions of the Royal Society B: Biological Sciences 357:1153-1170. https://doi. org/10.1098/rstb.2002.1117

Smith, A. D. M., K. J. Sainsbury, and R. A. Stevens. 1999. Implementing effective fisheries-management systems-management strategy evaluation and the Australian partnership approach. ICES Journal of Marine Science 56:967-979. https://doi. org/10.1006/jmsc. 1999.0540
Solomon, J. N., M. C. Gavin, and M. L. Gore. 2015. Detecting and understanding non-compliance with conservation rules. Biological Conservation 189:1-4. https://doi.org/10.1016/j. biocon.2015.04.028

Soofi, M., A. Ghoddousi, T. Zeppenfeld, S. Shokri, M. Soufi, L. Egli, A. Jafari, M. Ahmadpour, A. Qashqaei, T. Ghadirian, M. Filla, B. Kiabi, N. Balkenhol, M. Waltert, and I. Khorozyan. 2019. Assessing the relationship between illegal hunting of ungulates, wild prey occurrence and livestock depredation rate by large carnivores. Journal of Applied Ecology 56:365-374. https://doi. org/10.1111/1365-2664.13266

Stephenson, R. L., A. J. Benson, K. Brooks, A. Charles, P. Degnbol, C. M. Dichmont, M. Kraan, S. Pascoe, S. D. Paul, A. Rindorf, and M. Wiber. 2017. Practical steps toward integrating economic, social and institutional elements in fisheries policy and management. ICES Journal of Marine Science 74:1981-1989. https://doi.org/10.1093/icesjms/fsx057

Struebig, M. J., M. Linkie, N. J. Deere, D. J. Martyr, B. Millyanawati, S. C. Faulkner, S. C. Le Comber, F. M. Mangunjaya, N. Leader-Williams, J. E. McKay, and F. A. V. St. John. 2018. Addressing human-tiger conflict using socio-ecological information on tolerance and risk. Nature Communications 9:3455. https://doi.org/10.1038/s41467-018-05983-y

Suutarinen, J., and I. Kojola. 2017. Poaching regulates the legally hunted wolf population in Finland. Biological Conservation 215:11-18. https://doi.org/10.1016/j.biocon.2017.08.031

Travers, H., L. J. Archer, G. Mwedde, D. Roe, J. Baker, A. Plumptre, A. Rwetsiba, and E. J. Milner-Gulland. 2019a. Understanding complex drivers of wildlife crime to design effective conservation interventions. Conservation Biology 33:1296-1306. https://doi.org/10.1111/cobi.13330

Travers, H., M. Selinske, A. Nuno, A. Serban, F. Mancini, T. Barychka, E. Bush, R. A. Rasolofoson, J. E. M. Watson, and E. J. Milner-Gulland. 2019b. A manifesto for predictive conservation. Biological Conservation 237:12-18. https://doi. org/10.1016/j.biocon.2019.05.059

Whitman, K. L., A. M. Starfield, H. Quadling, and C. Packer. 2007. Modeling the effects of trophy selection and environmental disturbance on a simulated population of African lions. Conservation Biology 21:591-601. https://doi.org/10.1111/ j.1523-1739.2007.00700.x

Young, J. C., K. Searle, A. Butler, P. Simmons, A. D. Watt, and A. Jordan. 2016. The role of trust in the resolution of conservation conflicts. Biological Conservation 195:196-202. https://doi. org/10.1016/j.biocon.2015.12.030 


\section{Appendix 1}

Manager and user budget choice

The observed resource population size is passed on to the manager sub-model, whose role is to enact a harvesting quota that best minimizes deviations from the managerspecific target abundance. Choice of harvest quota by the manager is implemented using a genetic algorithm that finds an adaptive - but not necessarily optimal - policy, thereby mimicking a goal-oriented process prone to human error (see Duthie et al. 2018 for more details). The resulting quota is then transferred to the harvest submodel, which also calls a genetic algorithm to determine a harvest that minimizes deviation from an user-specific target abundance whilst taking into account varying levels of user budget/

In the GMSE framework, both manager and user actions are constrained by their respective budgets (Duthie et al. 2018). A high budget for the manager increases the range of quotas they can set, and therefore enables them to exert more control on population management. In contrast, the user budget defines the maximum harvest that can be obtained by the user in the absence of management. When the user budget is high but the manager budget is low, the user is able to remove more animals from the population as the manager is unable to set a high enough quota.

Although interesting in their own right, scenarios in which the manager is unable to control the user, or in which the user is unable to fulfil the quotas set by the manager, would consistently lead to over- or under-exploitation of the wildlife population, 
respectively. Our focus in this study is to instead consider scenarios in which both manager and user possess the means to effectively manage the wildlife population. This enables us to focus on quantifying how, and to what extent, conflicting objectives prevent the attainment of management targets that would otherwise be met. This requires selecting values for manager and user budgets that enable a given target to be met in the absence of perturbations caused by potential disagreements.

To evaluate the influence of manager and user budgets on management outcomes, we carried out simulations in which both budgets were varied between 0 and 10,000. For each budget combination we ran 10 management time steps and recorded wildlife population size at the final time step. Simulations were carried out with $\mu$ set to $0.2, \mathrm{~K}$ to 2000 , and population target to 1000 individuals.

When user budget is low, the wildlife population grows beyond the population target to carrying capacity regardless of manager budget (Fig A1.1). This reflects a situation in which even the maximum possible harvesting capacity is insufficient to prevent a managed population from growing. In contrast, when manager budget is low and the ability of the user to affect the wildlife population increases, extinction becomes more likely. This illustrates a situation in which a manager cannot control a highly effective harvesting strategy. This could occur, for example, if the manager repeatedly underestimated harvesting power. 


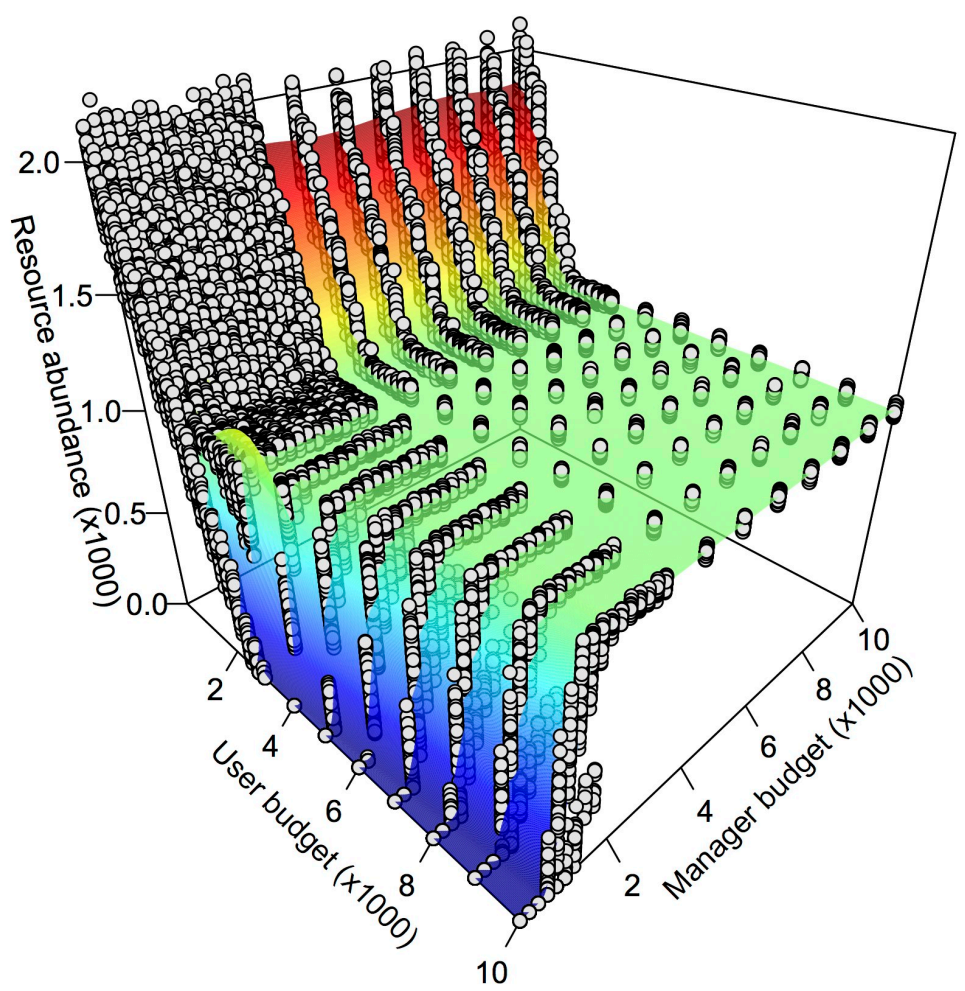

Fig. A1.1. Natural resource abundance observed as a function of user and manager budgets in the absence of conflict over management objectives. Dots denote resource abundance during the final management time step for each iteration of a user and manager budget combination. The fitted surface was obtained from a Poisson generalized additive model with a smooth tensor product representing the interaction between user and manager budgets. The surface colours are indicative of natural resource abundance $($ red $=$ under-exploitation; green $=$ target; blue = over-exploitation $)$. The management target remained constant at 1000 individuals across the different combinations of user and manager budget. The natural resource population followed a logistic growth with an intrinsic growth rate of 0.2 and a carrying capacity of 2000 individuals.

Most importantly, we find that the management target can be achieved only for a subset of all manager and user budget combinations. In theory, any combination belonging to this subset will result in effective management in the absence of external perturbations. Based on these results, we chose to vary user budget each management 
year between 5,000 and 10,000, while maintaining the manager budget at 10,000. This accounts for stochastic fluctuations in user budget that may affect harvesting capacity.

\section{Literature cited}

Duthie A. B., J. J. Cusack, I. J. Jones, J. Minderman, E. B. Nilsen, R. A. Pozo, R. A., S. Rakotonarivo, B. Van Moorter, and N. Bunnefeld. 2018. GMSE: an R package for generalised management strategy evaluation. Methods in Ecology and Evolution 9: 2396-2401. 


\section{Appendix 2}

$\mathrm{R}$ code to simulate natural resource management in the presence of conflict, lobbying and non-compliance.

Below we provide an annotated R script that can be used to replicate the simulations presented in this study.

The only $\mathrm{R}$ package required to run a simulation is GMSE (Duthie et al. 2018).

require( 'GMSE')

The following values can be varied to test the effect of target, budget, decisionmaking bias and user compliance on management outcome:

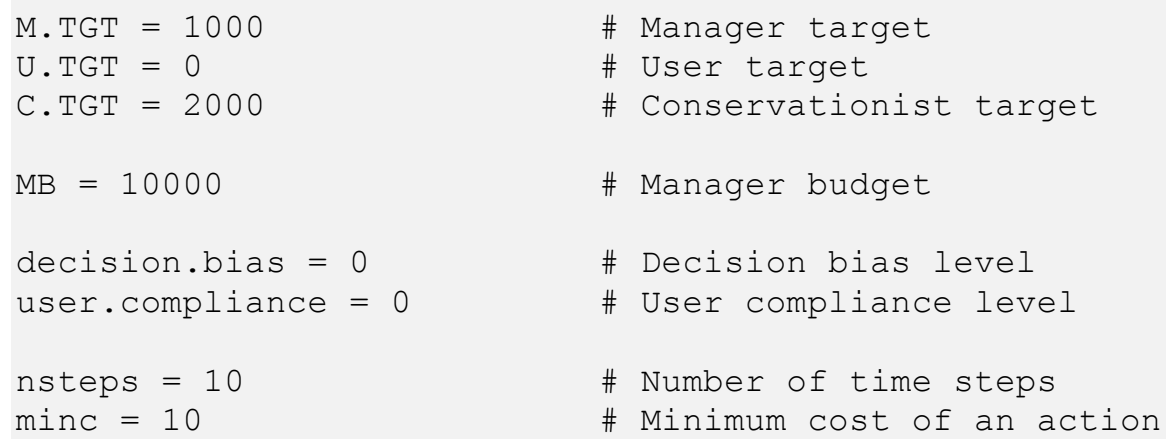

The following functions define the population growth model, the observation model, lobbying pressure by users and conservationists, and illegal harvesting pressure by users.

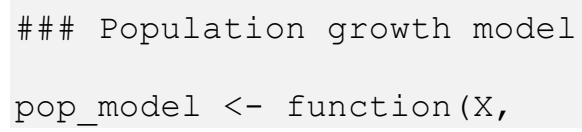




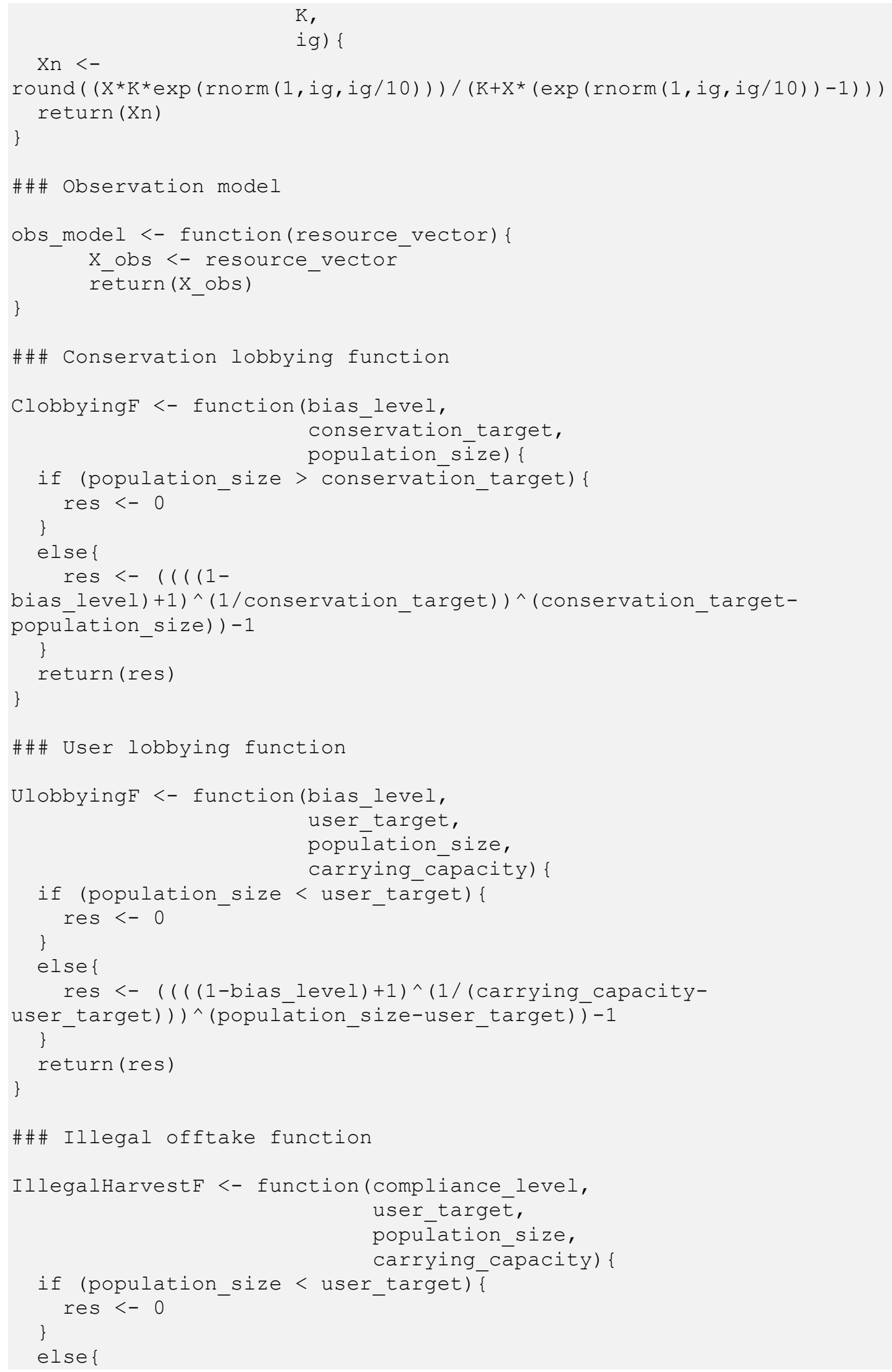




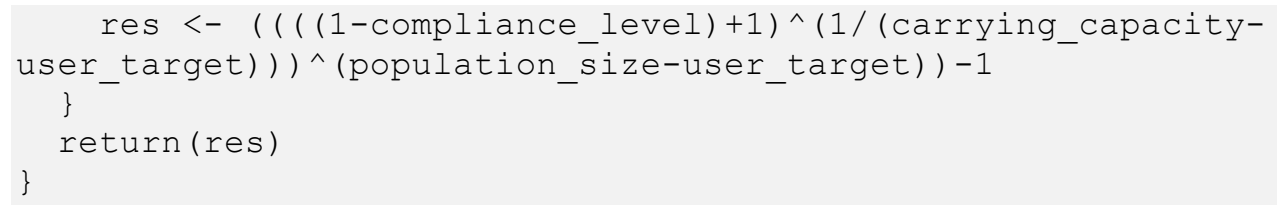

Population parameters are set to:

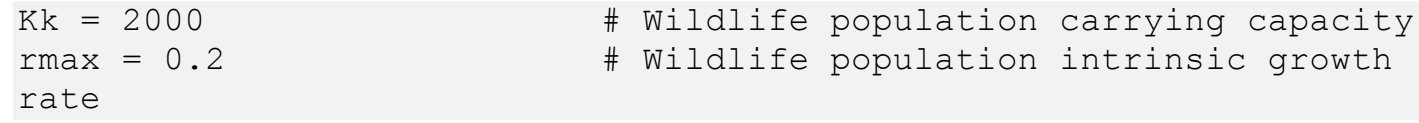

The code below runs one management iteration of nsteps time steps under user

lobbying for given values of M.TGT, U.TGT, C.TGT, MB, decision.bias, user.compliance and minc specified above. All other values appearing in the calls to gmse_apply not defined above are default values as described in ${ }^{1}$.

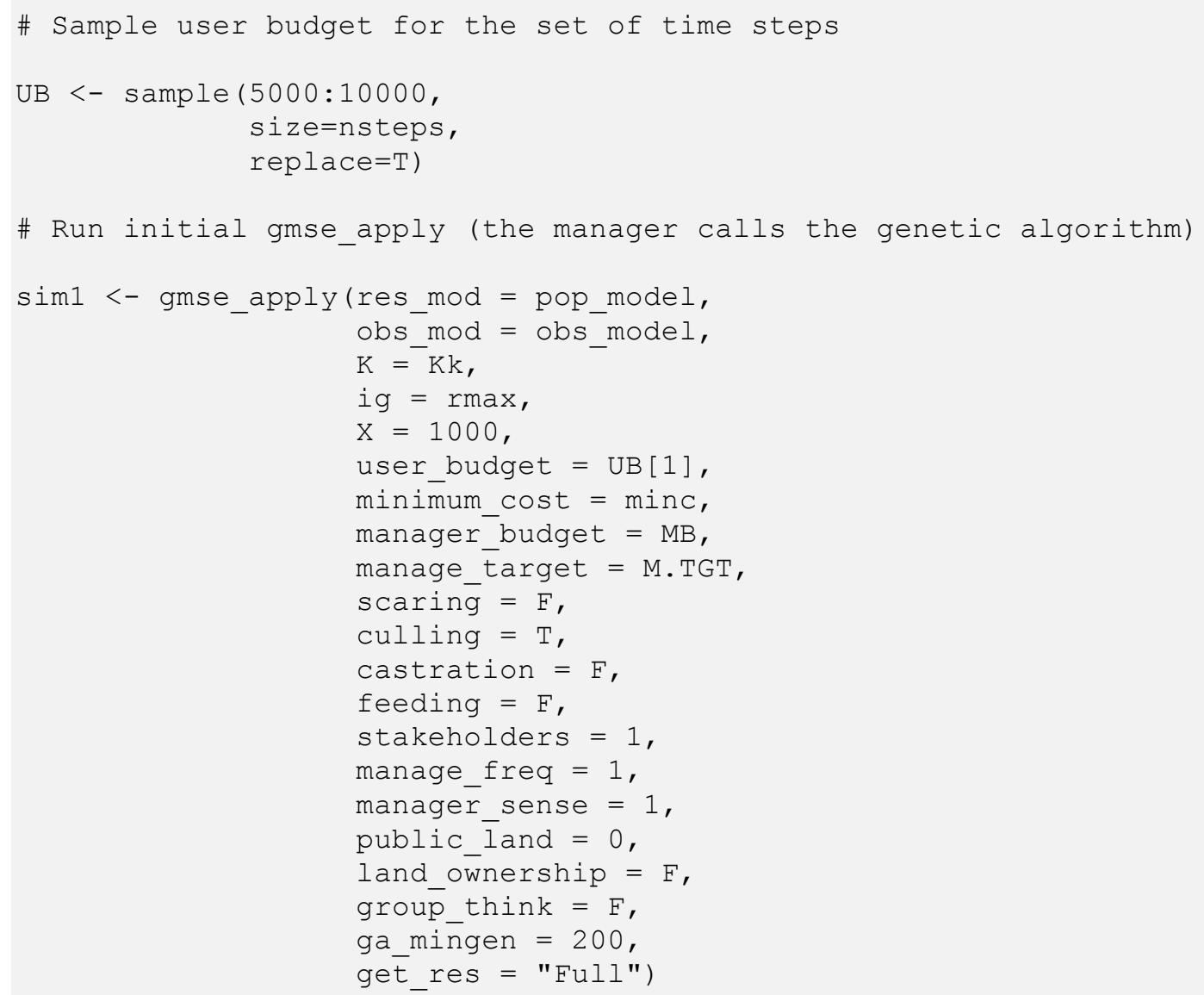




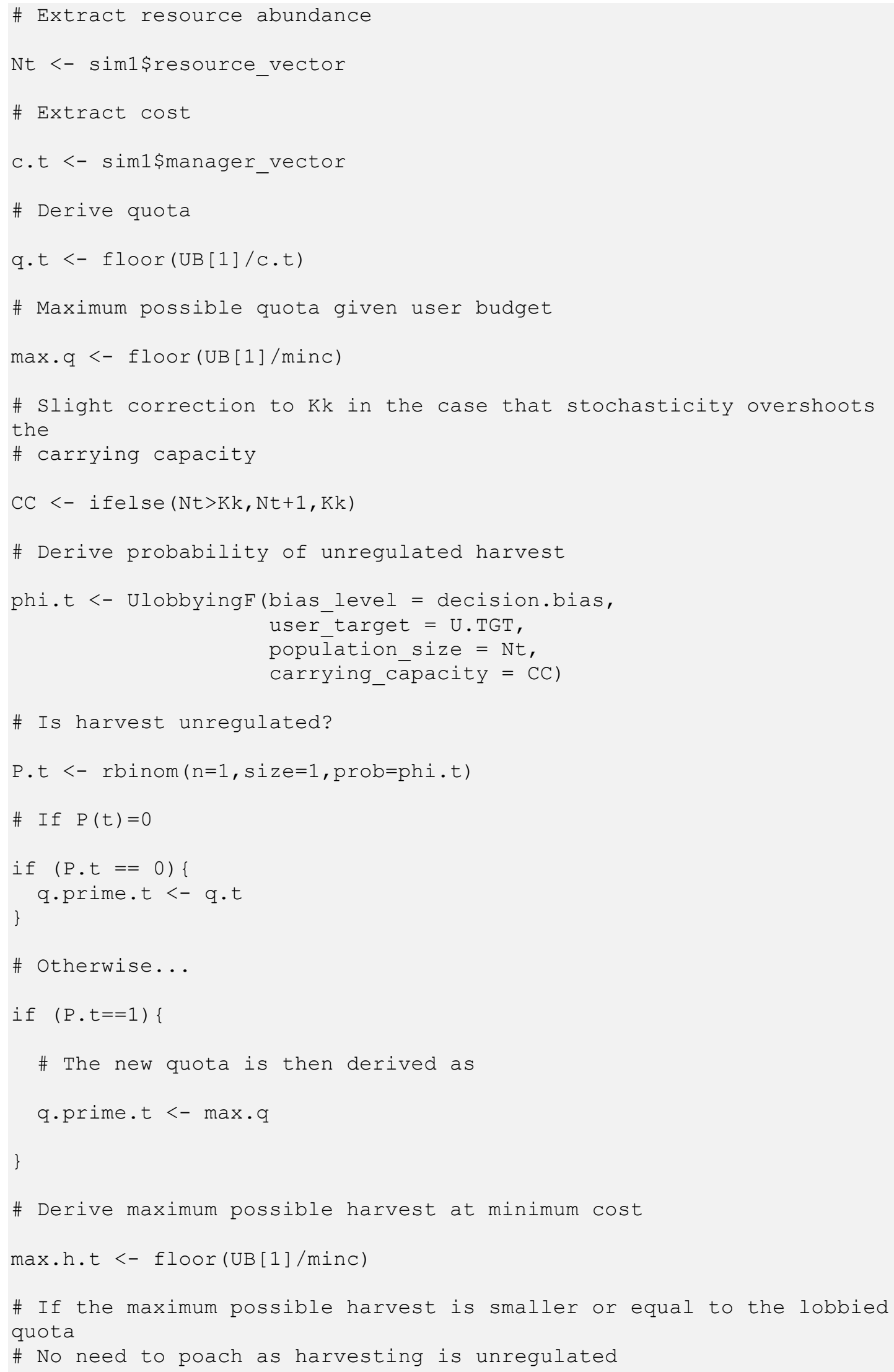




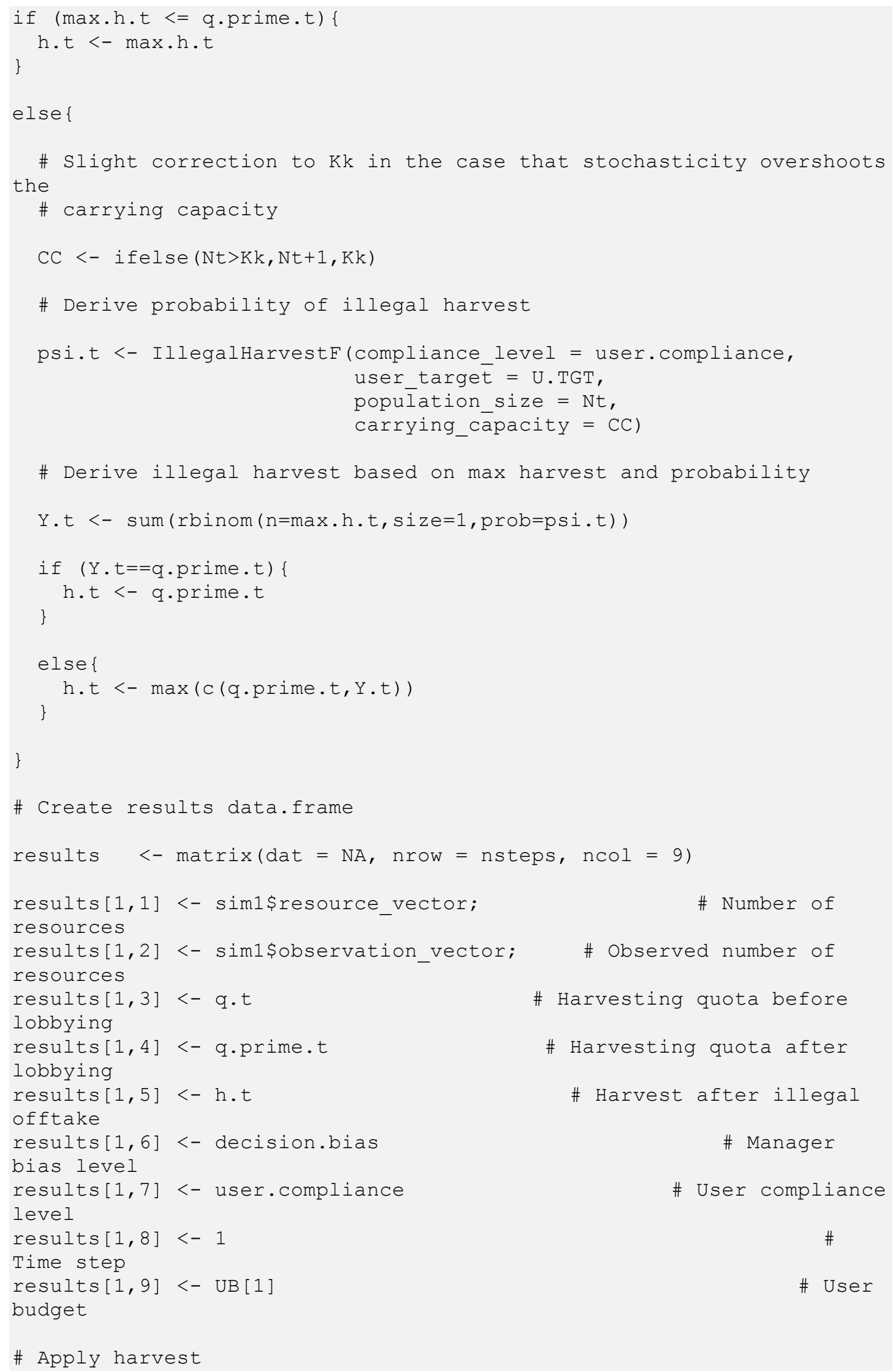




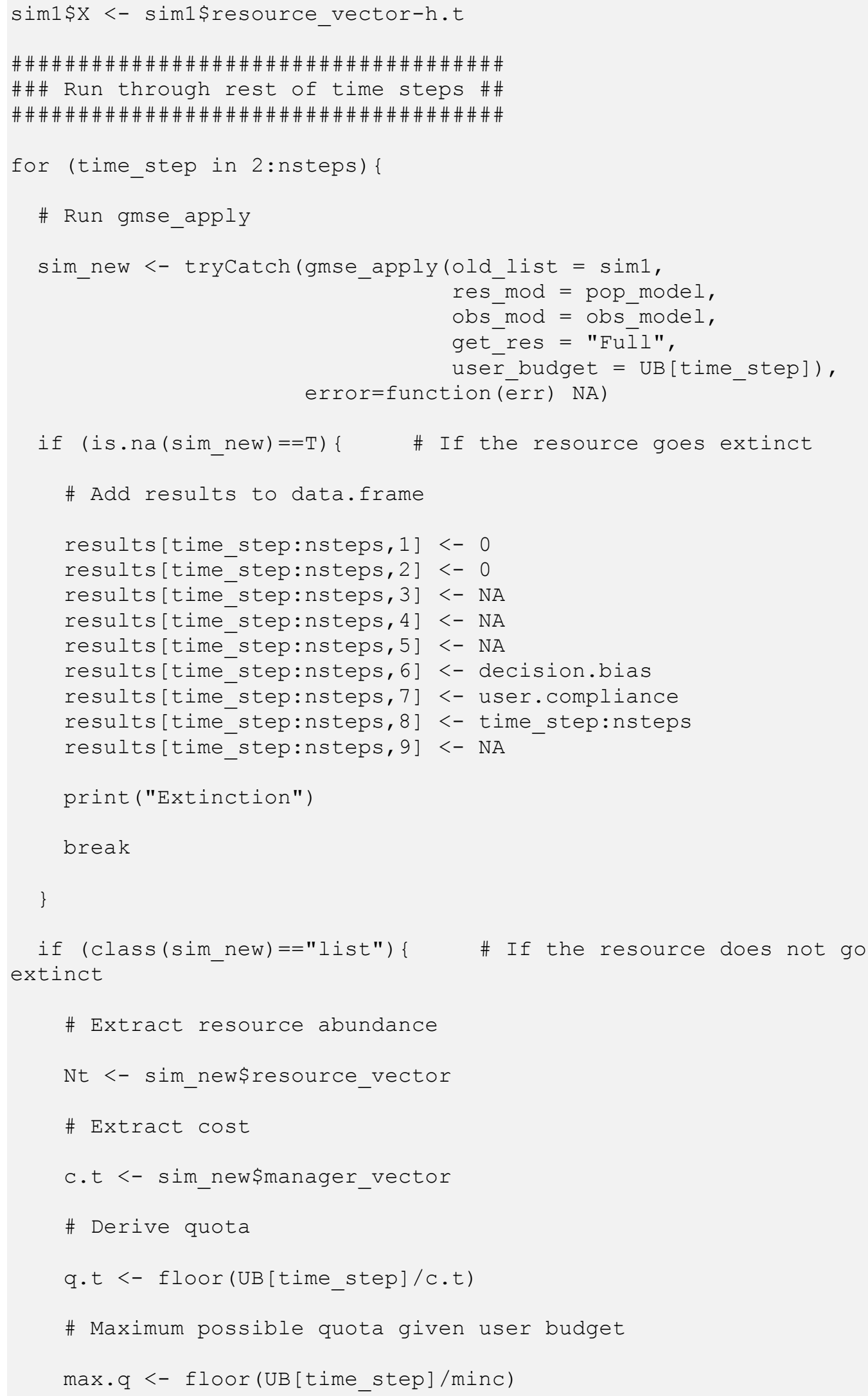




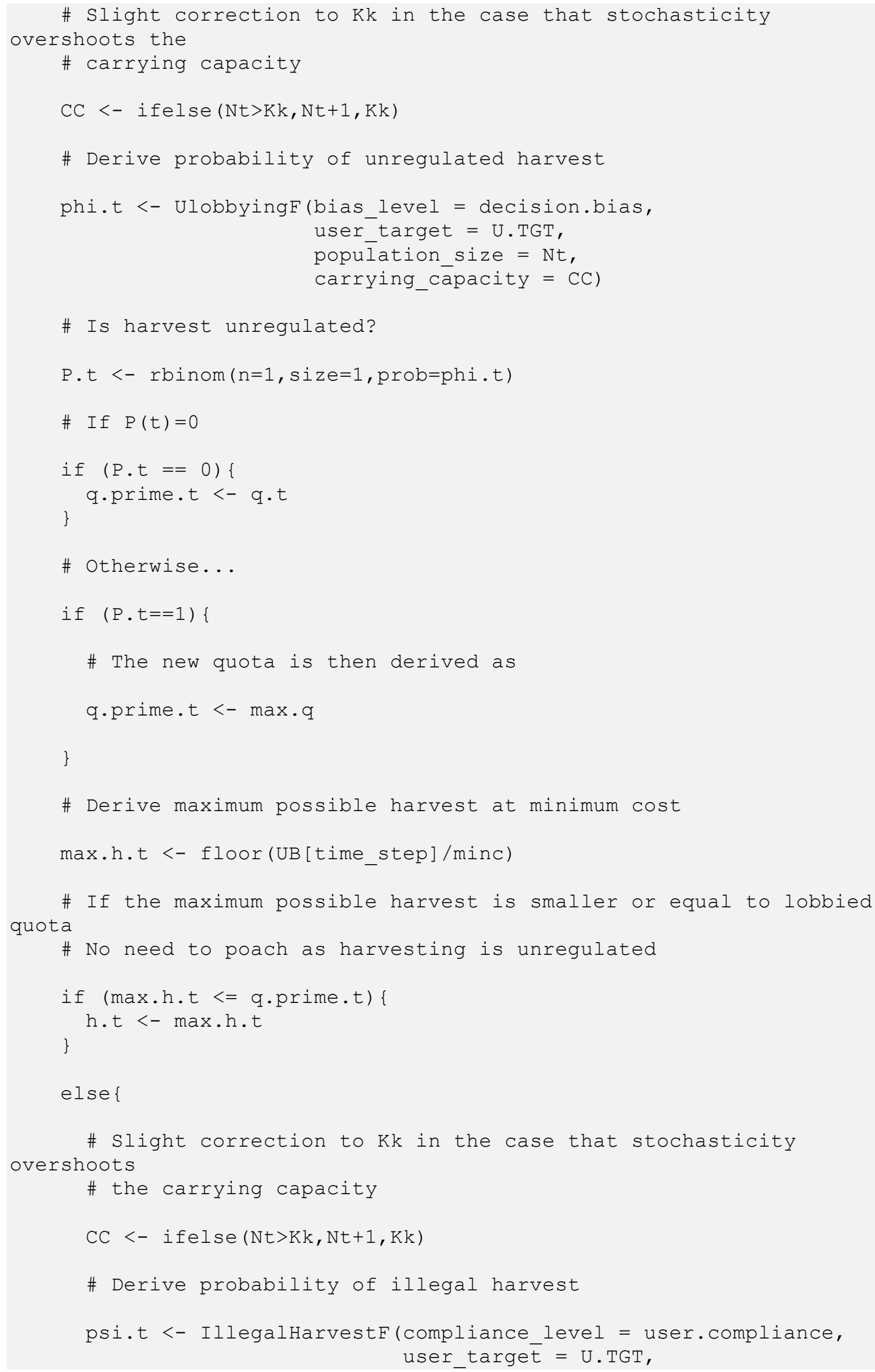




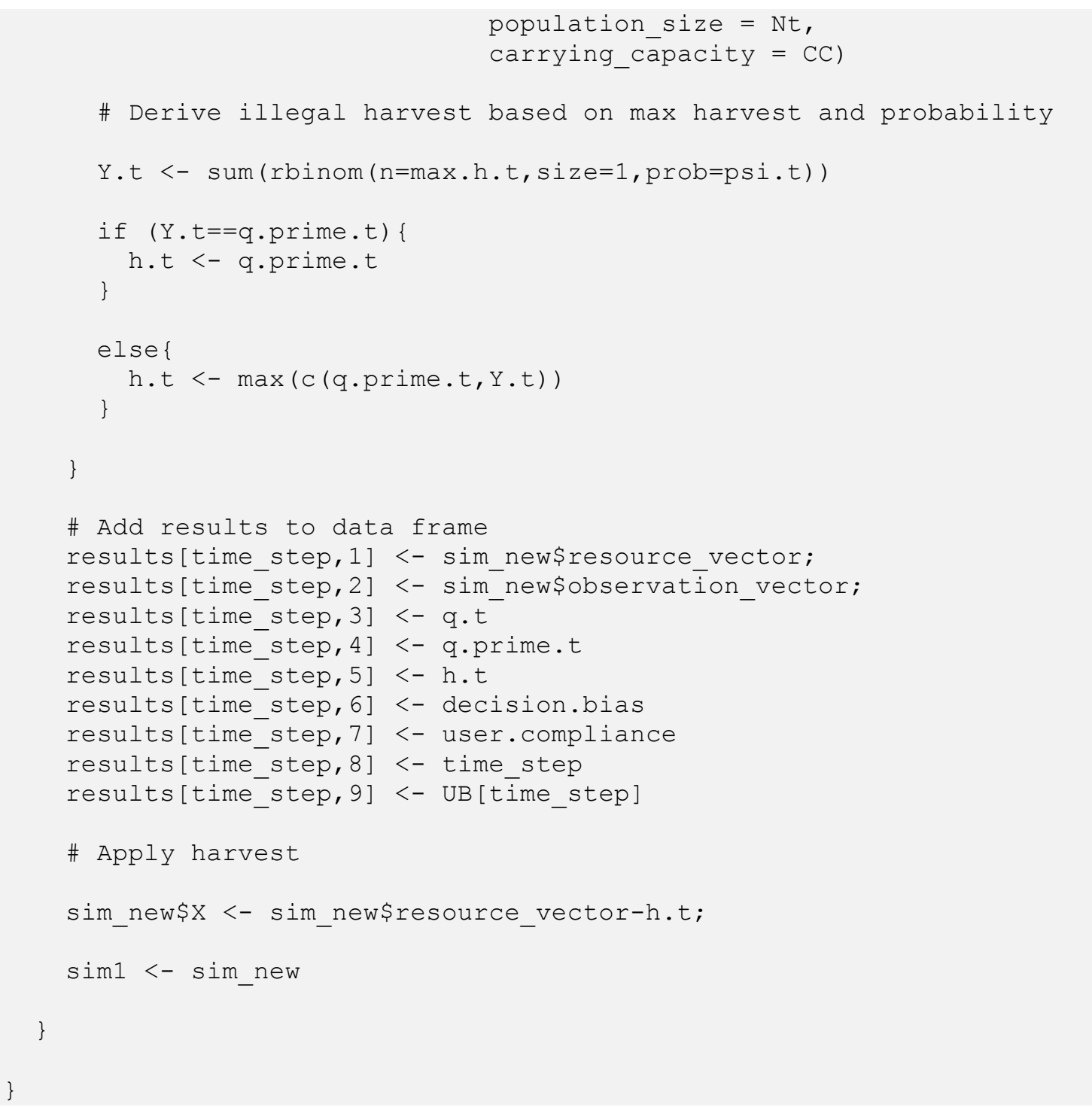

The following code runs one management iteration of nsteps time steps under conservationist lobbying for given values of M. TGT, U. TGT, C.TGT, MB, decision.bias, user.compliance and minc specified above. All other values appearing in the calls to gmse_apply not defined above are default values as described in ${ }^{1}$.

\# Sample user budget for the set of time steps

UB <- sample (5000:10000,

size=nsteps, 


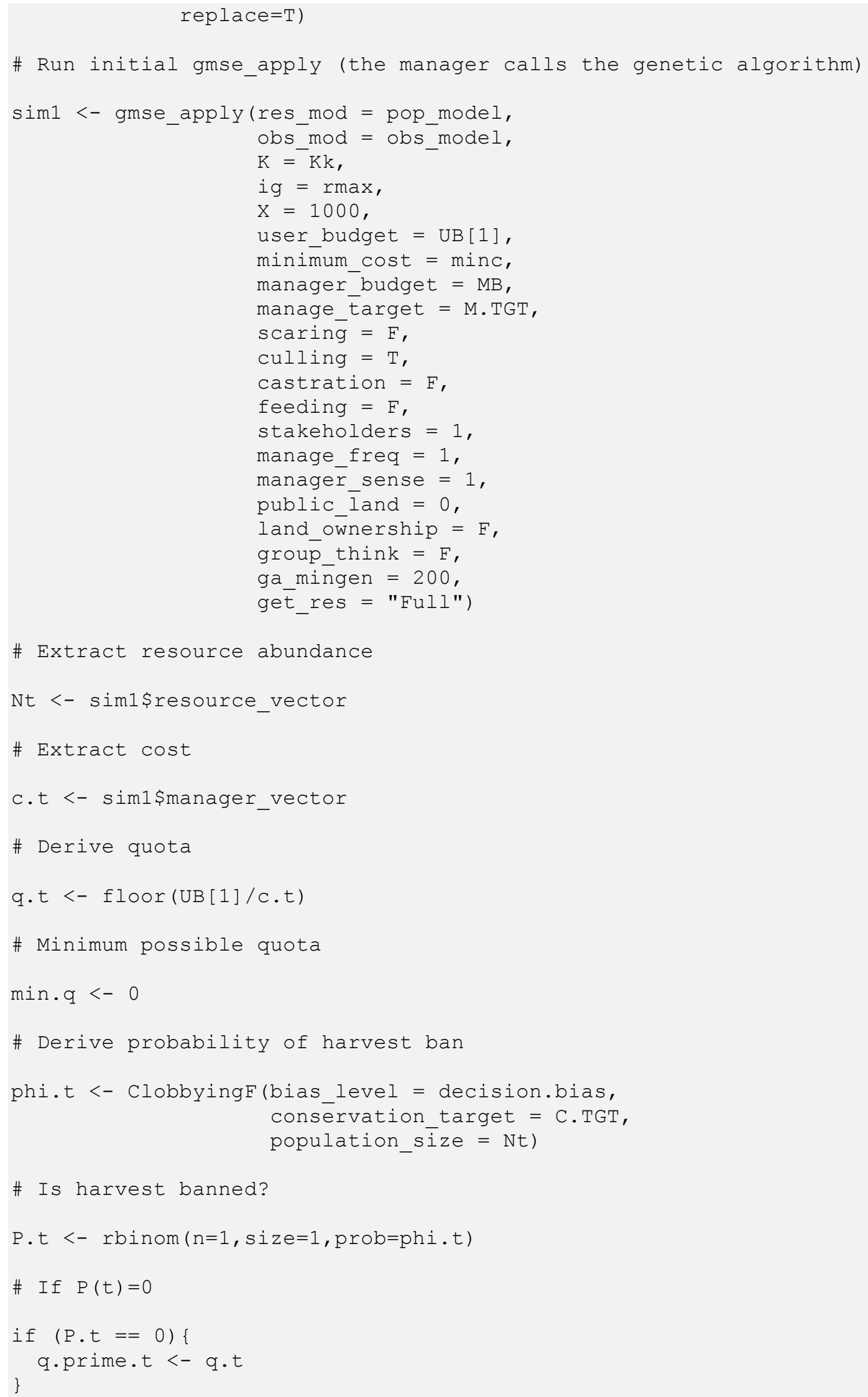




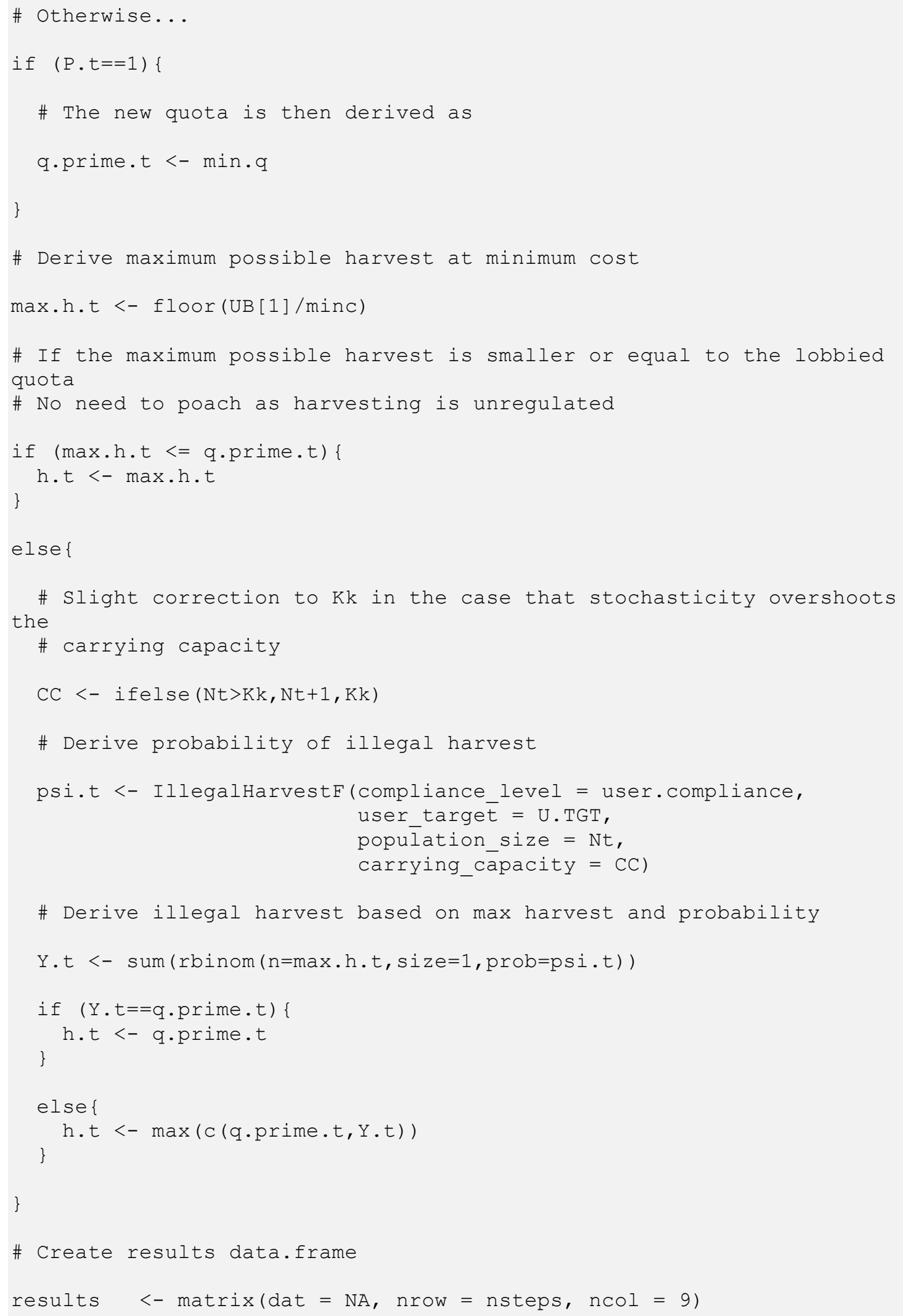




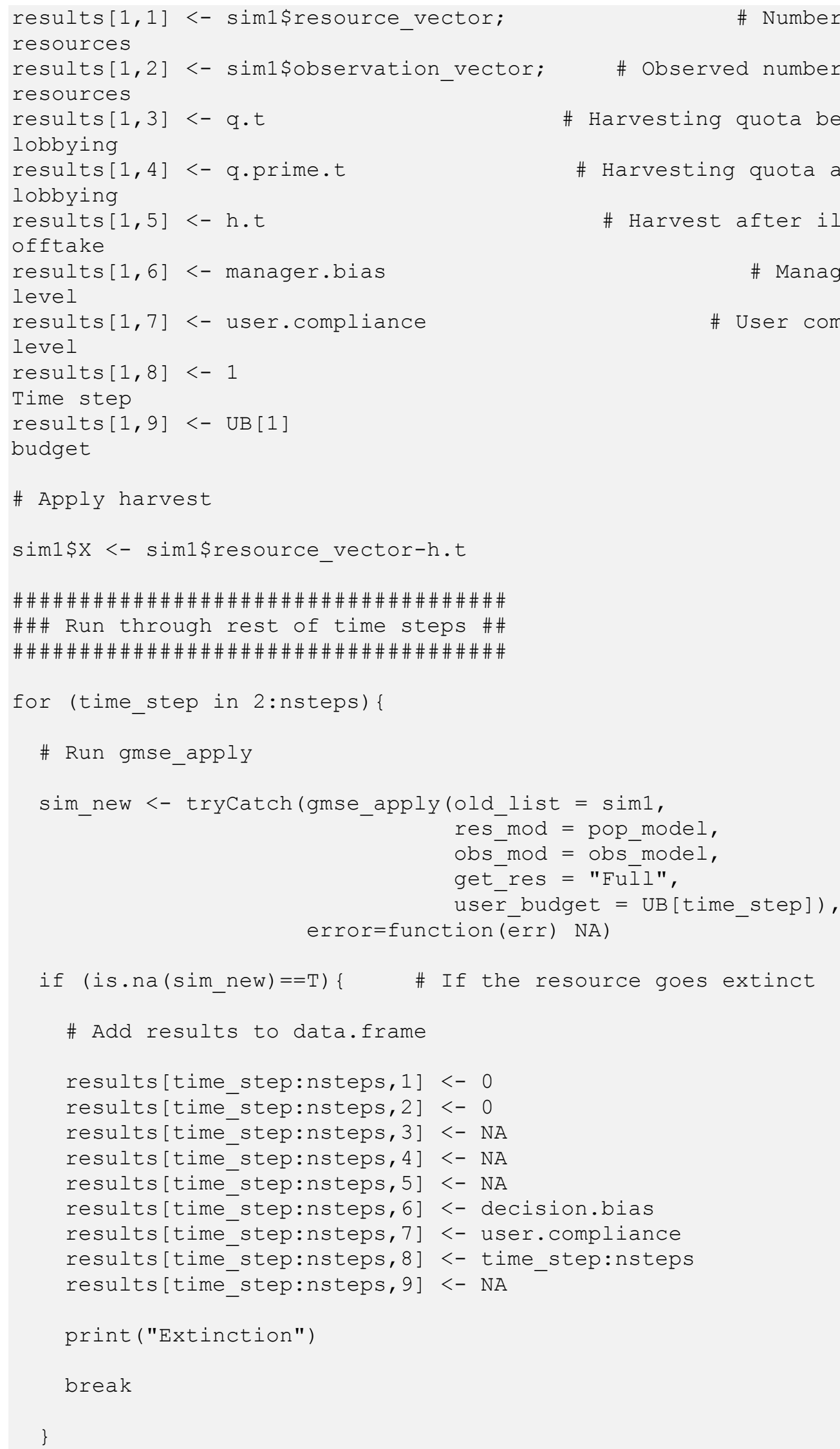




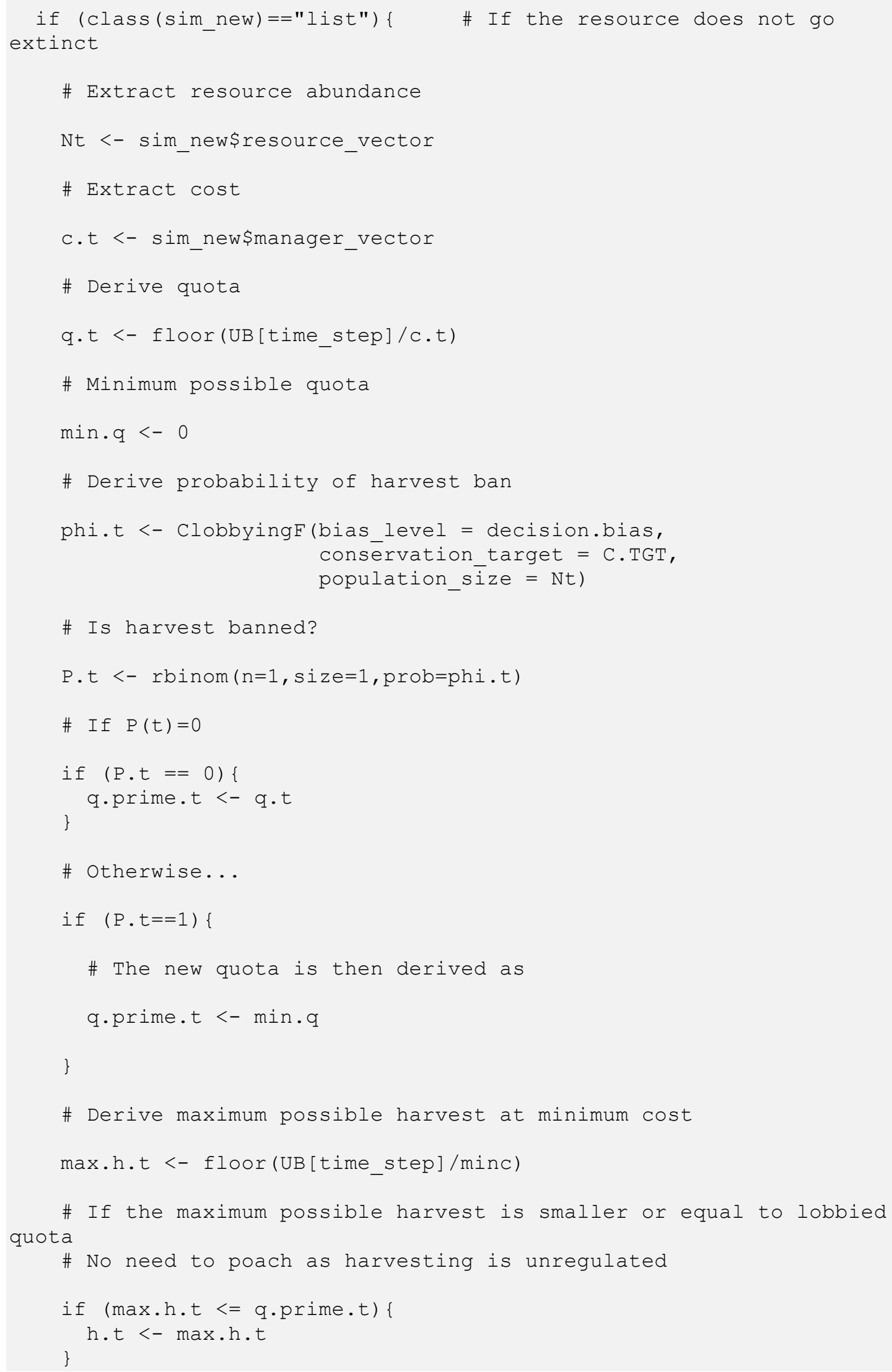




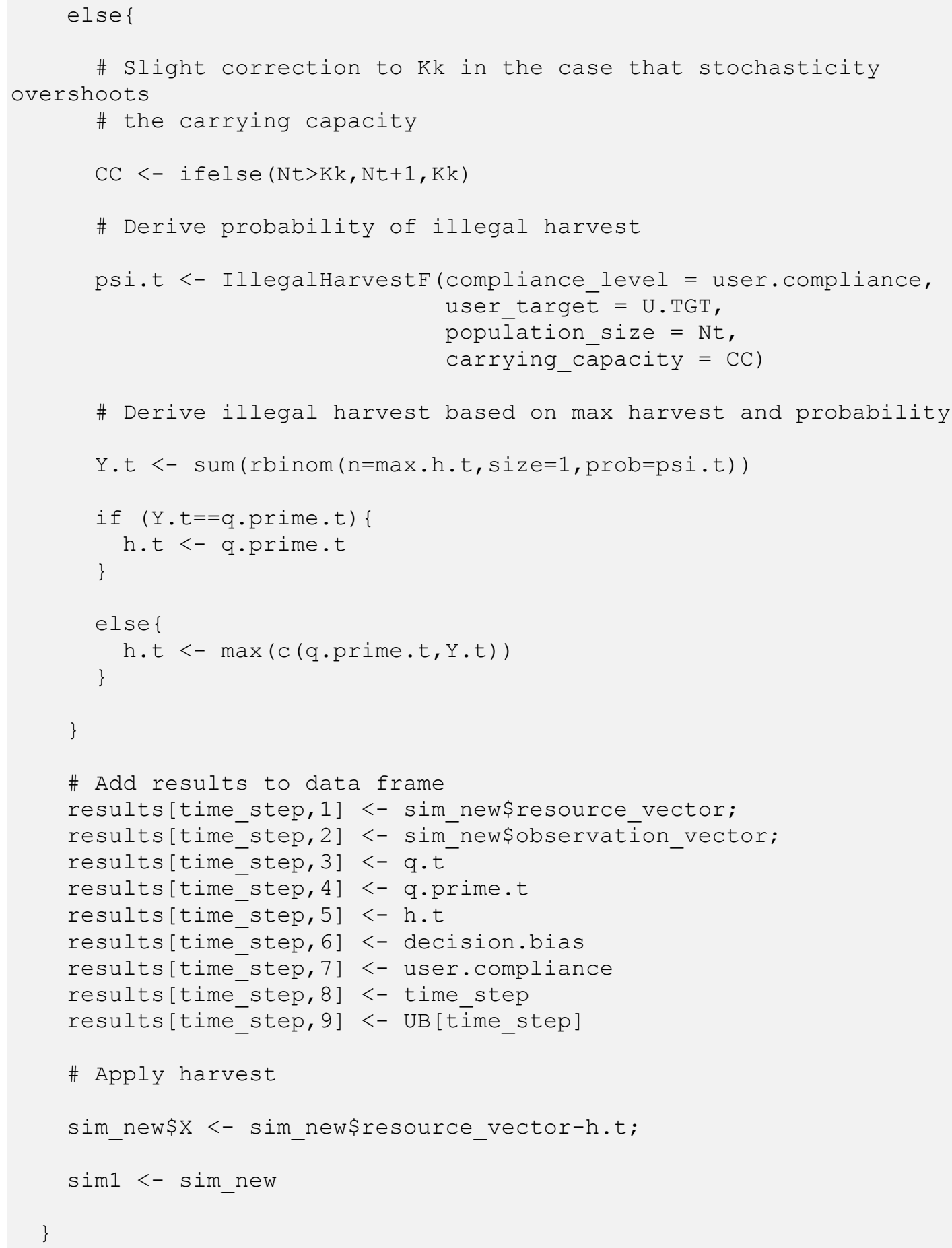

\section{Literature cited}


Duthie A. B., J. J. Cusack, I. J. Jones, J. Minderman, E. B. Nilsen, R. A. Pozo, R. A., S. Rakotonarivo, B. Van Moorter, and N. Bunnefeld. 2018. GMSE: an R package for generalised management strategy evaluation. Methods in Ecology and Evolution 9: 2396-2401. 


\section{Appendix 3}

Definition and value of set and derived parameters.

Table A3.1. Definition and value of set and derived parameters.

\begin{tabular}{|c|c|c|}
\hline Parameter & "Definition & Value(s) used \\
\hline \multicolumn{3}{|c|}{ Set parameters } \\
\hline$T$ & Number of management years & 10 \\
\hline$N_{i}$ & Initial resource population size & 1000 \\
\hline$K$ & Resource population carrying capacity & 2000 \\
\hline$r$ & Resource population intrinsic growth rate & $0.1,0.2,0.3$ \\
\hline$\sigma$ & Growth rate standard deviation & $r / 10$ \\
\hline$N_{M}$ & Manager target abundance & 1000 \\
\hline$N_{U}$ & User target abundance & 0 \\
\hline$N_{C}$ & Conservation target abundance & 2000 \\
\hline$B_{M}$ & $\begin{array}{l}\text { Manager budget - an abstract quantity that controls } \\
\text { the ability of the manager to set higher quotas }\end{array}$ & 10000 \\
\hline$B_{U}$ & $\begin{array}{l}\text { User budget - an abstract quantity that controls the } \\
\text { ability of the user to harvest resources }\end{array}$ & $\begin{array}{l}\text { Varied between } 5000 \text { and } \\
10000 \text { (see Appendix 1) }\end{array}$ \\
\hline$I_{C}$ & $\begin{array}{l}\text { Level of decision-making bias in favor of } \\
\text { conservation objectives }\end{array}$ & $\begin{array}{l}\text { Varied between } 0 \text { (no bias) } \\
\text { and } 1 \text { (complete bias) }\end{array}$ \\
\hline$I_{U}$ & $\begin{array}{l}\text { Level of decision-making bias in favor of user } \\
\text { objectives }\end{array}$ & $\begin{array}{l}\text { Varied between } 0 \text { (no bias) } \\
\text { and } 1 \text { (complete bias) }\end{array}$ \\
\hline$c_{\min }$ & $\begin{array}{l}\text { Arbitrary quantity representing the minimum cost of } \\
\text { harvesting a resource }\end{array}$ & 10 \\
\hline E & $\begin{array}{l}\text { Level of user compliance with harvest quota set by } \\
\text { the manager }\end{array}$ & $\begin{array}{l}\text { Varied between } 0 \text { (no } \\
\text { compliance) and } 1 \text { (full } \\
\text { compliance) }\end{array}$ \\
\hline
\end{tabular}

\section{Derived parameters}


$H_{\max }$

$\Phi_{\text {Conservation }}$

$\Phi_{U s e r}$

$\Psi$

Y

$H$
Harvest quota set by the manager prior to lobbying

Harvest quota set by the manager post lobbying

Maximum number of resources that can be harvested

by the user

Probability of successful lobbying for a harvesting

ban by conservation groups

Probability of successful lobbying for unregulated harvest

Probability that the user will successfully harvest one individual resource unit from the population

Hypothetical illegal harvest that the user compares to $Q^{\prime}$ in order to decide on final harvest

Final user harvest
Derived from the genetic

algorithm

$0, Q$ or $H_{\max }$ (see main text)

See Equation 4 in main text

See Equation 2 in main text

See Equation 3 in main text

See Equation 5 in main text

$B\left(H_{\max }, \Psi\right)$

$\max \left(Y, Q^{\prime}\right)$ 


\section{Appendix 4}

Classification protocol used to assign decision-making bias and user compliance levels to harvested IUCN Red List species.

We compared predictions from our model against data on 206 terrestrial harvested species from the International Union for the Conservation of Nature's (IUCN) Red List of Threatened Species. We considered species belonging to the orders Anseriformes (geese and ducks, $N=37$ ), Cetartiodactyla (even-toed ungulates, $N=90$ ) and Carnivora (carnivores, $N=79$ ) as these are commonly targeted by subsistence, recreational and trophy hunting activities globally (Di Minin et al. 2019, Hill et al. 2019).

Using the "advanced search" option on the IUCN Red List website (https://www.iucnredlist.org/, accessed $14^{\text {th }}$ January 2019), we filtered species by criteria relating to Taxonomy ("Anseriformes", "Cetartiodactyla" and "Carnivora"), Red List Category ("NT or LR/nt" and "LC or LR/lc"), and Threats ("Intentional use (species is the target)"). We only considered species listed as Least Concern or Near Threatened so as to minimize confounding factors associated with threat status. Filtering resulted in a total of 206 species to which the classification of decisionmaking bias and user compliance shown in Fig. A3.1 was applied (see below). More specifically, we classified each species according to 1) its stated population trend at the latest assessment (decreasing, stable or increasing), 2) the type of harvesting it was most commonly under (unregulated, regulated or banned), and 3) the level of illegal harvest most commonly reported for a population (low, medium or high). We 
then used population trend as a measure of management outcome, harvesting type as a measure of decision-making bias (with unregulated and banned taken to reflect prouser and pro-conservation biases), and illegal harvest level as a measure of user compliance. Classifications were carried out by two of the authors and subsequently compared to ensure consistency. 


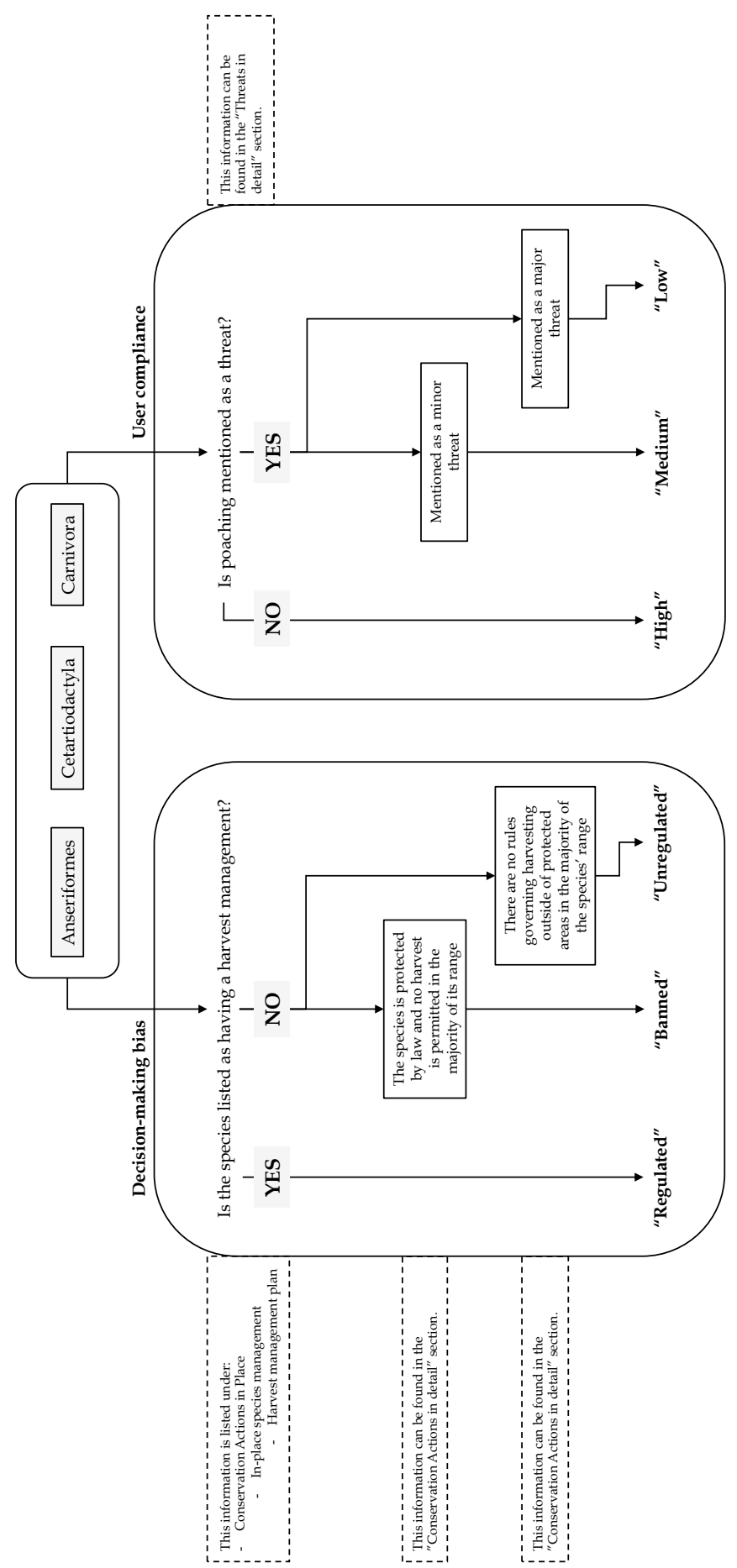

Fig. A4.1. Classification protocol used to assign decision-making bias and user compliance levels to harvested IUCN Red List species. 


\section{Appendix 5}

Mean population growth and extinction probability surfaces for simulated resource population growth rates of 0.1 and 0.3 .

Predicted patterns of management outcome for different combinations of management bias and user compliance are similar to those shown for a population growth rate of 0.2 in Fig. 3 in the main text. This indicates that predicted patterns are not sensitive to choice of resource population growth rate.
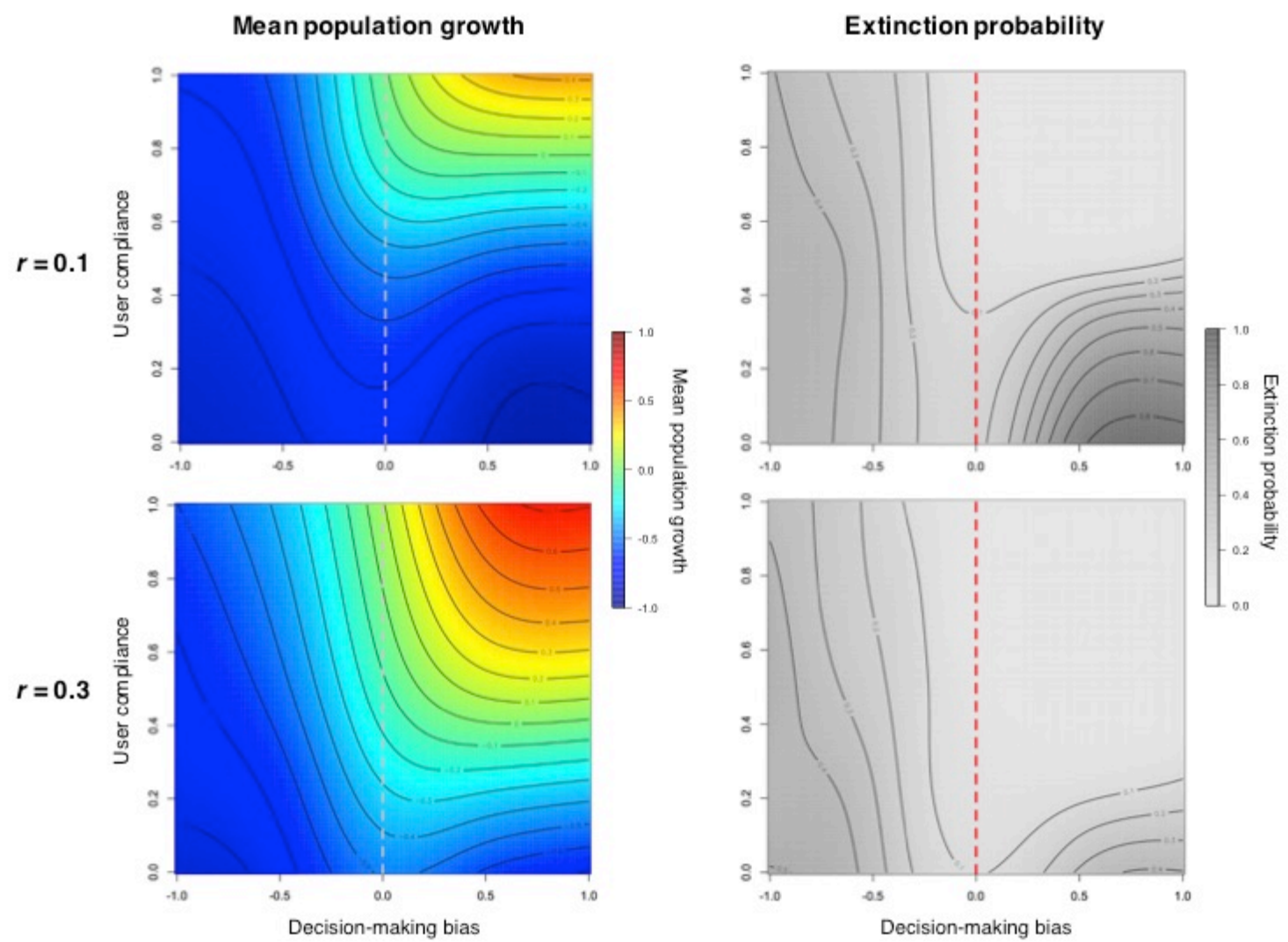

Fig. A5.1. Mean population growth and extinction probability over a 10-year management period as a function of decision-making bias and user compliance for simulated intrinsic population growth rates $(r)$ of 0.1 and 0.3 . Decision-making bias ranges from entirely pro-user (-1, harvest is always unregulated) to pro-conservation 
$(+1$, harvest is always banned), with 0 representing a scenario in which manager quota decisions cannot be lobbied. When user compliance is 0 , users will always partake in illegal harvesting while a value of 1 ensures users will fully comply with the quota put forward by the manager (post-lobbying). The 2D contour surfaces were obtained from generalized additive models with decision-making bias and user compliance specified as tensor product smooths. Dashed vertical lines (light grey and red) denote unbiased management decisions. 


\section{Appendix 6}

Harvested IUCN Red List species.

Table A6.1. List of IUCN Red List species and associated population trend, decisionmaking bias and user compliance levels.

\begin{tabular}{|c|c|c|c|c|c|c|}
\hline Order & Species & Scientific Name & $\begin{array}{l}\text { Red List } \\
\text { Category }\end{array}$ & $\begin{array}{l}\text { Population } \\
\text { Trend }\end{array}$ & $\begin{array}{l}\text { Management } \\
\text { Bias }\end{array}$ & $\begin{array}{l}\text { User } \\
\text { Compliance }\end{array}$ \\
\hline Cetartiodactyla & Natal red duiker & $\begin{array}{l}\text { Cephalophus } \\
\text { natalensis }\end{array}$ & $\mathrm{LC}$ & Decreasing & Unregulated & High \\
\hline Cetartiodactyla & Maxwell's duiker & $\begin{array}{l}\text { Philantomba } \\
\text { maxwellii }\end{array}$ & $\mathrm{LC}$ & Decreasing & Unregulated & Low \\
\hline Cetartiodactyla & Common wildebeest & $\begin{array}{l}\text { Connochaetes } \\
\text { taurinus }\end{array}$ & $\mathrm{LC}$ & Stable & Unregulated & Medium \\
\hline Cetartiodactyla & Waterbuck & Kobus ellipsiprymnus & $\mathrm{LC}$ & Decreasing & Unregulated & Medium \\
\hline Cetartiodactyla & Red flanked duiker & Cephalophus rufilatus & $\mathrm{LC}$ & Decreasing & Unregulated & Medium \\
\hline Cetartiodactyla & Bohor reedbuck & Redunca redunca & $\mathrm{LC}$ & Decreasing & Unregulated & Medium \\
\hline Cetartiodactyla & Wild boar & Sus scrofa & $\mathrm{LC}$ & Stable & Unregulated & High \\
\hline Cetartiodactyla & Alpine ibex & Capra ibex & $\mathrm{LC}$ & Increasing & Regulated & High \\
\hline Cetartiodactyla & Pyrenean chamois & Rupicapra pyrenaica & $\mathrm{LC}$ & Increasing & Regulated & High \\
\hline Cetartiodactyla & Moose & Alces alces & $\mathrm{LC}$ & Increasing & Regulated & High \\
\hline Cetartiodactyla & Tufted deer & $\begin{array}{l}\text { Elaphodus } \\
\text { cephalophus }\end{array}$ & NT & Decreasing & Unregulated & Medium \\
\hline Cetartiodactyla & Nilgai & $\begin{array}{l}\text { Boselaphus } \\
\text { tragocamelus }\end{array}$ & $\mathrm{LC}$ & Stable & Regulated & High \\
\hline Cetartiodactyla & Bongo & $\begin{array}{l}\text { Tragelaphus } \\
\text { eurycerus }\end{array}$ & NT & Decreasing & Regulated & Medium \\
\hline Cetartiodactyla & Sitatunga & Tragelaphus spekii & LC & Decreasing & Regulated & High \\
\hline Cetartiodactyla & Muskox & Ovibos moschatus & $\mathrm{LC}$ & Stable & Regulated & High \\
\hline Cetartiodactyla & Markhor & Capra falconeri & NT & Decreasing & Regulated & Low \\
\hline Cetartiodactyla & Himalayan goral & Naemorhedus goral & NT & Decreasing & Regulated & High \\
\hline Cetartiodactyla & Himalayan tahr & $\begin{array}{l}\text { Hemitragus } \\
\text { jemlahicus }\end{array}$ & NT & Decreasing & Unregulated & Low \\
\hline Cetartiodactyla & Sulawesi warty pig & Sus celebensis & NT & Decreasing & Unregulated & High \\
\hline Cetartiodactyla & Gray brocket & Mazama gouazoubira & $\mathrm{LC}$ & Decreasing & Banned & Medium \\
\hline Cetartiodactyla & Southern pudu & Pudu puda & NT & Decreasing & Banned & Medium \\
\hline Cetartiodactyla & Blue duiker & $\begin{array}{l}\text { Philantomba } \\
\text { monticola }\end{array}$ & $\mathrm{LC}$ & Decreasing & Unregulated & Medium \\
\hline Cetartiodactyla & Black duiker & Cephalophus niger & $\mathrm{LC}$ & Decreasing & Unregulated & Medium \\
\hline Cetartiodactyla & Klipspringer & $\begin{array}{l}\text { Oreotragus } \\
\text { oreotragus }\end{array}$ & $\mathrm{LC}$ & Stable & Unregulated & High \\
\hline Cetartiodactyla & Common warthog & $\begin{array}{l}\text { Phacochoerus } \\
\text { africanus }\end{array}$ & $\mathrm{LC}$ & Decreasing & Unregulated & Medium \\
\hline Cetartiodactyla & European roe deer & Capreolus capreolus & $\mathrm{LC}$ & Increasing & Regulated & High \\
\hline Cetartiodactyla & Japanese serow & Capricornis crispus & $\mathrm{LC}$ & Increasing & Regulated & High \\
\hline Cetartiodactyla & Guanaco & Lama guanicoe & $\mathrm{LC}$ & Increasing & Regulated & High \\
\hline Cetartiodactyla & Oribi & Ourebia ourebi & $\mathrm{LC}$ & Decreasing & Unregulated & High \\
\hline
\end{tabular}




\begin{tabular}{|c|c|c|c|c|c|c|}
\hline Cetartiodactyla & Topi & Damaliscus lunatus & LC & Decreasing & Unregulated & Medium \\
\hline Cetartiodactyla & Southern lechwe & Kobus leche & NT & Decreasing & Unregulated & Low \\
\hline Cetartiodactyla & Roan antelope & Hippotragus equinus & LC & Decreasing & Unregulated & Medium \\
\hline Cetartiodactyla & Rothschild's giraffe & $\begin{array}{l}\text { Giraffa } \\
\text { camelopardalis }\end{array}$ & NT & Increasing & Banned & High \\
\hline Cetartiodactyla & Hartebeest & $\begin{array}{l}\text { Alcelaphus } \\
\text { buselaphus }\end{array}$ & LC & Decreasing & Unregulated & Medium \\
\hline Cetartiodactyla & Salt's dikdik & Madoqua saltiana & LC & Stable & Unregulated & High \\
\hline Cetartiodactyla & Kirk's dikdik & Madoqua kirkii & LC & Stable & Unregulated & High \\
\hline Cetartiodactyla & Northern red muntjac & Muntiacus vaginalis & LC & Decreasing & Regulated & Low \\
\hline Cetartiodactyla & Sika deer & Cervus nippon & LC & Increasing & Regulated & High \\
\hline Cetartiodactyla & Lesser kudu & Tragelpahus imberbis & NT & Decreasing & Regulated & Medium \\
\hline Cetartiodactyla & African buffalo & Syncerus caffer & LC & Decreasing & Regulated & Medium \\
\hline Cetartiodactyla & Bushbuck & Tragelaphus scriptus & LC & Stable & Unregulated & High \\
\hline Cetartiodactyla & Pronghorn & $\begin{array}{l}\text { Antilocapra } \\
\text { americana }\end{array}$ & LC & Stable & Regulated & High \\
\hline Cetartiodactyla & Peter's duiker & $\begin{array}{l}\text { Cephalophus } \\
\text { callipygus }\end{array}$ & LC & Decreasing & Unregulated & Medium \\
\hline Cetartiodactyla & Bay duiker & Cephalophus dorsalis & NT & Decreasing & Unregulated & Low \\
\hline Cetartiodactyla & Eastern tur & Capra cylindricornis & NT & Decreasing & Regulated & Low \\
\hline Cetartiodactyla & Reeves' muntjac & Muntiacus reevesi & LC & Decreasing & Unregulated & Low \\
\hline Cetartiodactyla & Vicuna & Vicugna vicugna & LC & Increasing & Regulated & High \\
\hline Cetartiodactyla & Siberian roe deer & Capreolus pygargus & LC & Decreasing & Regulated & Low \\
\hline Cetartiodactyla & White tailed deer & $\begin{array}{l}\text { Odocoileus } \\
\text { virginianus }\end{array}$ & LC & Stable & Regulated & High \\
\hline Cetartiodactyla & Red serow & Capricornis rubidus & NT & Decreasing & Banned & Low \\
\hline Cetartiodactyla & Suni & Nesotragus moschatus & LC & Stable & Unregulated & High \\
\hline Cetartiodactyla & Common duiker & Sylvicapra grimmia & LC & Decreasing & Unregulated & High \\
\hline Cetartiodactyla & Thomson's gazelle & Eudorcas thomsonii & LC & Decreasing & Regulated & Medium \\
\hline Cetartiodactyla & American bison & Bison bison & NT & Stable & Regulated & High \\
\hline Cetartiodactyla & White bellied duiker & $\begin{array}{l}\text { Cephalophus } \\
\text { leucogaster }\end{array}$ & NT & Decreasing & Unregulated & High \\
\hline Cetartiodactyla & Grant's gazelle & Nanger granti & LC & Decreasing & Unregulated & Medium \\
\hline Cetartiodactyla & Comon eland & Tragelaphus oryx & LC & Stable & Regulated & Medium \\
\hline Cetartiodactyla & Tarim red deer & Cervus hanglu & LC & Increasing & Regulated & Medium \\
\hline Cetartiodactyla & Argali & Ovis ammon & NT & Decreasing & Regulated & Low \\
\hline Cetartiodactyla & Collared peccary & Pecari tajacu & LC & Stable & Regulated & Medium \\
\hline Cetartiodactyla & Red river hog & $\begin{array}{l}\text { Potamochoerus } \\
\text { porcus }\end{array}$ & LC & Decreasing & Unregulated & High \\
\hline Cetartiodactyla & Red deer & Cervus elaphus & LC & Increasing & Regulated & High \\
\hline Cetartiodactyla & Mongolian gazelle & Procapra gutturosa & LC & Stable & Regulated & Medium \\
\hline Cetartiodactyla & Wapiti & Cervus canadensis & LC & Increasing & Regulated & Medium \\
\hline Cetartiodactyla & Chiru & Pantholops hodgsonii & NT & Increasing & Banned & Medium \\
\hline Cetartiodactyla & Nyala & Tragelaphus angasii & LC & Stable & Regulated & High \\
\hline Cetartiodactyla & Palawan bearded pig & Sus ahoenobarbus & NT & Decreasing & Banned & Low \\
\hline Cetartiodactyla & Harvey's duiker & Cephalophus harveyi & LC & Decreasing & Unregulated & Medium \\
\hline
\end{tabular}




\begin{tabular}{|c|c|c|c|c|c|c|}
\hline Cetartiodactyla & Mongalla gazelle & Eudorcas albonotata & $\mathrm{LC}$ & Stable & Unregulated & High \\
\hline Cetartiodactyla & $\begin{array}{l}\text { Greater } \\
\text { chevrotain }\end{array} \quad$ oriental & Tragulus napu & $\mathrm{LC}$ & Decreasing & Regulated & Low \\
\hline Cetartiodactyla & Pampas deer & $\begin{array}{l}\text { Ozotoceros } \\
\text { bezoarticus }\end{array}$ & NT & Decreasing & Banned & High \\
\hline Cetartiodactyla & Himalaya serow & Capricornis thar & NT & Decreasing & Banned & Low \\
\hline Cetartiodactyla & Black fronted duiker & $\begin{array}{l}\text { Caphalophus } \\
\text { nigrifrons }\end{array}$ & $\mathrm{LC}$ & Decreasing & Banned & High \\
\hline Cetartiodactyla & Southern red muntjac & Muntiacus muntjak & $\mathrm{LC}$ & Decreasing & Regulated & Medium \\
\hline Cetartiodactyla & Blesbok & Damaliscus pygargus & $\mathrm{LC}$ & Stable & Regulated & High \\
\hline Cetartiodactyla & Mountain goat & Oreamnos americanus & $\mathrm{LC}$ & Stable & Regulated & High \\
\hline Cetartiodactyla & $\begin{array}{l}\text { Amazonian } \\
\text { brocket }\end{array}$ & Mazama nemorivaga & LC & Decreasing & Unregulated & High \\
\hline Cetartiodactyla & $\begin{array}{l}\text { Bornean } \\
\text { muntjac }\end{array}$ & Muntiacus atherodes & NT & Decreasing & Banned & Medium \\
\hline Cetartiodactyla & Forest hog & $\begin{array}{l}\text { Hylochoerus } \\
\text { meinertzhageni }\end{array}$ & $\mathrm{LC}$ & Decreasing & Unregulated & Medium \\
\hline Cetartiodactyla & Ogilby's duiker & Cephalophus ogilbyi & $\mathrm{LC}$ & Decreasing & Unregulated & Medium \\
\hline Cetartiodactyla & Steenbok & $\begin{array}{l}\text { Raphicerus } \\
\text { campestris }\end{array}$ & $\mathrm{LC}$ & Stable & Unregulated & High \\
\hline Cetartiodactyla & Cape grysbok & Raphicerus melanotis & $\mathrm{LC}$ & Stable & Regulated & High \\
\hline Cetartiodactyla & Chinkara & Gazella bennettii & LC & Decreasing & Banned & High \\
\hline Cetartiodactyla & Generuk & Litocranius walleri & NT & Decreasing & Unregulated & Medium \\
\hline Cetartiodactyla & Tibetan gazelle & Procapra picticaudata & NT & Decreasing & Banned & High \\
\hline Cetartiodactyla & Chinese serow & $\begin{array}{l}\text { Capricornis } \\
\text { milneedwardsii }\end{array}$ & NT & Decreasing & Unregulated & Medium \\
\hline Cetartiodactyla & Weyn's duiker & Cephalophus weynsi & LC & Decreasing & Unregulated & Medium \\
\hline Cetartiodactyla & Southern reedbuck & Redunca arundinum & $\mathrm{LC}$ & Stable & Unregulated & High \\
\hline Cetartiodactyla & Puku & Kobus vardonii & NT & Decreasing & Unregulated & Low \\
\hline Cetartiodactyla & Sharpe's grysbok & Raphicerus sharpei & LC & Stable & Unregulated & High \\
\hline Anseriforme & Common goldeneye & Bucephala clangula & LC & Stable & Unregulated & High \\
\hline Anseriforme & Garganey & Spatual querquedula & $\mathrm{LC}$ & Decreasing & Unregulated & High \\
\hline Anseriforme & Harlequin duck & $\begin{array}{l}\text { Histrionicus } \\
\text { histrionicus }\end{array}$ & $\mathrm{LC}$ & Increasing & Banned & High \\
\hline Anseriforme & Brown teal & Anas chlorotis & NT & Increasing & Banned & High \\
\hline Anseriforme & Surf scoter & $\begin{array}{l}\text { Melanitta } \\
\text { perspicillata }\end{array}$ & $\mathrm{LC}$ & Decreasing & Unregulated & High \\
\hline Anseriforme & Greater scaup & Aythya marila & LC & Decreasing & Regulated & High \\
\hline Anseriforme & Ferruginous duck & Aythya nyroca & NT & Decreasing & Banned & Low \\
\hline Anseriforme & King eider & Somateria spectabilis & $\mathrm{LC}$ & Decreasing & Unregulated & High \\
\hline Anseriforme & Bean goose & Anser fabalis & $\mathrm{LC}$ & Decreasing & Regulated & Medium \\
\hline Anseriforme & Northen pintail & Anas acuta & LC & Decreasing & Regulated & High \\
\hline Anseriforme & African pygmy goose & Nettapus auritus & LC & Decreasing & Unregulated & High \\
\hline Anseriforme & Northern shoveler & Spatula clypeata & LC & Decreasing & Regulated & High \\
\hline Anseriforme & Greylag goose & Anser anser & $\mathrm{LC}$ & Increasing & Regulated & High \\
\hline Anseriforme & Common shelduck & Tadorna tadorna & LC & Increasing & Banned & High \\
\hline Anseriforme & Pink footed goose & Anser brachyrhynchus & LC & Increasing & Regulated & High \\
\hline Anseriforme & Brent goose & Branta bernicla & $\mathrm{LC}$ & Increasing & Regulated & High \\
\hline Anseriforme & Baikal teal & Sibirionetta formosa & LC & Increasing & Banned & High \\
\hline
\end{tabular}




\begin{tabular}{|c|c|c|c|c|c|c|}
\hline Anseriforme & Barrow's goldeneye & Bucephala islandica & LC & Increasing & Regulated & High \\
\hline Anseriforme & Red breasted merganser & Mergus serrator & LC & Stable & Unregulated & High \\
\hline Anseriforme & Blue billed duck & Oxyura australis & NT & Stable & Unregulated & High \\
\hline Anseriforme & Southern pochard & $\begin{array}{l}\text { Netta } \\
\text { erythrophthalma }\end{array}$ & $\mathrm{LC}$ & Decreasing & Unregulated & High \\
\hline Anseriforme & American comb duck & Sarkidiornis sylvicoal & LC & Decreasing & Unregulated & High \\
\hline Anseriforme & Fulvous whistling duck & Dendrocygna bicolor & $\mathrm{LC}$ & Decreasing & Unregulated & High \\
\hline Anseriforme & African black duck & Anas sparsa & LC & Decreasing & Unregulated & High \\
\hline Anseriforme & Orinoco goose & Neochen jubata & NT & Decreasing & Unregulated & High \\
\hline Anseriforme & Flying steamerduck & $\begin{array}{l}\text { Tachyeres } \\
\text { patachonicus }\end{array}$ & LC & Decreasing & Unregulated & High \\
\hline Anseriforme & Sunda teal & Anas gibberifrons & NT & Stable & Regulated & High \\
\hline Anseriforme & Falcated duck & Mareca falcata & NT & Decreasing & Unregulated & High \\
\hline Anseriforme & Siberian scoter & Melanitta stejnegeri & LC & Decreasing & Unregulated & High \\
\hline Anseriforme & African comb duck & $\begin{array}{l}\text { Sarkidiornis } \\
\text { melanotos }\end{array}$ & $\mathrm{LC}$ & Decreasing & Unregulated & High \\
\hline Anseriforme & Spectacled eider & Somateria fischeri & NT & Decreasing & Unregulated & High \\
\hline Anseriforme & Barnacle goose & Brenta leucopsis & $\mathrm{LC}$ & Increasing & Regulated & High \\
\hline Anseriforme & Northen screamer & Chauna chavaria & NT & Decreasing & Banned & Medium \\
\hline Anseriforme & Hartlaub's duck & Pteronetta hartlaubii & LC & Decreasing & Unregulated & High \\
\hline Anseriforme & Emperor goose & Anser canagicus & NT & Decreasing & Unregulated & High \\
\hline Anseriforme & Black scoter & Melanitta americana & NT & Decreasing & Unregulated & High \\
\hline Anseriforme & White winged scoter & Melanitta deglandi & LC & Decreasing & Unregulated & High \\
\hline Carnivora & African clawless otter & Aonyx capensis & NT & Decreasing & Unregulated & High \\
\hline Carnivora & Pine marten & Martes martes & LC & Stable & Regulated & Medium \\
\hline Carnivora & Beech marten & Martes foina & LC & Stable & Unregulated & High \\
\hline Carnivora & Northern racoon & Procyon lotor & LC & Increasing & Unregulated & High \\
\hline Carnivora & Common palm civet & $\begin{array}{l}\text { Paradoxurus } \\
\text { hermaphroditus }\end{array}$ & LC & Decreasing & Regulated & Medium \\
\hline Carnivora & Wolverine & Gulo gulo & $\mathrm{LC}$ & Decreasing & Regulated & Medium \\
\hline Carnivora & Bengal fox & Vulpes bengalensis & LC & Decreasing & Banned & High \\
\hline Carnivora & Margay & Leopardus wiedii & NT & Decreasing & Banned & Medium \\
\hline Carnivora & Eurasian otter & Lutra lutra & NT & Decreasing & Banned & Medium \\
\hline Carnivora & White nosed coati & Nasua narica & LC & Decreasing & Regulated & Medium \\
\hline Carnivora & Striped hyaena & Hyaena hyaena & NT & Decreasing & Regulated & Low \\
\hline Carnivora & American black bear & Ursus americanus & $\mathrm{LC}$ & Increasing & Regulated & High \\
\hline Carnivora & Banded mongoose & Mungos mungo & $\mathrm{LC}$ & Stable & Unregulated & High \\
\hline Carnivora & Eurasian lynx & Lynx lynx & $\mathrm{LC}$ & Stable & Regulated & High \\
\hline Carnivora & Wild cat & Felis silvestris & $\mathrm{LC}$ & Decreasing & Regulated & High \\
\hline Carnivora & Asiatic golden cat & Catopuma temminckii & NT & Decreasing & Banned & Medium \\
\hline Carnivora & Brown bear & Ursus arctos & LC & Stable & Regulated & High \\
\hline Carnivora & Spotted necked otter & Hydrictis maculicollis & NT & Decreasing & Unregulated & High \\
\hline Carnivora & Malay civet & Viverra tangalunga & LC & Stable & Unregulated & High \\
\hline Carnivora & Leopard cat & $\begin{array}{l}\text { Prionailurus } \\
\text { bengalensis }\end{array}$ & $\mathrm{LC}$ & Stable & Regulated & High \\
\hline
\end{tabular}




\begin{tabular}{|c|c|c|c|c|c|c|}
\hline Carnivora & Geoffroy's cat & Leopardus geoffroyi & LC & Stable & Banned & High \\
\hline Carnivora & Pallas's cat & Otocolobus manul & NT & Decreasing & Regulated & High \\
\hline Carnivora & Bat eared fox & Otocyon megalotis & $\mathrm{LC}$ & Stable & Unregulated & High \\
\hline Carnivora & Kinkajou & Poto flavus & $\mathrm{LC}$ & Decreasing & Unregulated & High \\
\hline Carnivora & Western polecat & Mustela putorius & $\mathrm{LC}$ & Decreasing & Regulated & Low \\
\hline Carnivora & South american coati & Nasua nasua & $\mathrm{LC}$ & Decreasing & Unregulated & High \\
\hline Carnivora & Eurasian badger & Meles meles & $\mathrm{LC}$ & Stable & Regulated & High \\
\hline Carnivora & $\begin{array}{l}\text { Molina's hog nosed } \\
\text { skunk }\end{array}$ & Conepatus chinga & $\mathrm{LC}$ & Decreasing & Unregulated & High \\
\hline Carnivora & Bobcat & Lynx rufus & $\mathrm{LC}$ & Stable & Regulated & High \\
\hline Carnivora & Ocelot & Leopardus pardalis & $\mathrm{LC}$ & Decreasing & Regulated & Medium \\
\hline Carnivora & Pampas cat & Leopardus colocolo & NT & Decreasing & Banned & Medium \\
\hline Carnivora & Kit fox & Vulpes macrotis & $\mathrm{LC}$ & Decreasing & Regulated & High \\
\hline Carnivora & Marbled cat & Pardofelis marmorata & NT & Decreasing & Banned & Medium \\
\hline Carnivora & Serval & Leptailurus serval & $\mathrm{LC}$ & Stable & Regulated & High \\
\hline Carnivora & Pampas fox & $\begin{array}{l}\text { Lycalopex } \\
\text { gymnocercus }\end{array}$ & $\mathrm{LC}$ & Stable & Regulated & High \\
\hline Carnivora & Culpeo & Lycalopex culpaeus & $\mathrm{LC}$ & Stable & Regulated & Medium \\
\hline Carnivora & American marten & Martes americana & $\mathrm{LC}$ & Decreasing & Regulated & High \\
\hline Carnivora & Brown palm civet & Paradoxurus jerdoni & $\mathrm{LC}$ & Stable & Unregulated & High \\
\hline Carnivora & Short tailed mongoose & Herpestes brachyurus & NT & Decreasing & Unregulated & High \\
\hline Carnivora & Spotted linsang & Prionodon pardicolor & $\mathrm{LC}$ & Decreasing & Banned & Medium \\
\hline Carnivora & Aardwolf & Proteles cristata & $\mathrm{LC}$ & Stable & Unregulated & High \\
\hline Carnivora & Masked palm civet & Paguma larvata & $\mathrm{LC}$ & Decreasing & Unregulated & Medium \\
\hline Carnivora & Arctic fox & Vulpes lagopus & $\mathrm{LC}$ & Stable & Regulated & High \\
\hline Carnivora & Honey badger & Mellivora capensis & $\mathrm{LC}$ & Decreasing & Banned & Medium \\
\hline Carnivora & Banded linsang & Prionodon linsang & $\mathrm{LC}$ & Decreasing & Banned & High \\
\hline Carnivora & Large indian civet & Viverra zibetha & $\mathrm{LC}$ & Decreasing & Banned & Low \\
\hline Carnivora & Long nosed mongoose & Herpestes naso & LC & Decreasing & Unregulated & High \\
\hline Carnivora & $\begin{array}{ll}\text { Stripe } & \text { necked } \\
\text { mongoose } & \end{array}$ & Herpestes vitticollis & $\mathrm{LC}$ & Stable & Banned & High \\
\hline Carnivora & Crab eating mongoose & Procyon cancrivorus & $\mathrm{LC}$ & Decreasing & Unregulated & High \\
\hline Carnivora & Steppe polecat & Mustela eversmanii & $\mathrm{LC}$ & Decreasing & Banned & Medium \\
\hline Carnivora & Marsh mongoose & Atilax paludinosus & $\mathrm{LC}$ & Decreasing & Unregulated & High \\
\hline Carnivora & Brown mongoose & Herpestes fuscus & $\mathrm{LC}$ & Stable & Unregulated & High \\
\hline Carnivora & $\begin{array}{l}\text { Humboldt's hog nosed } \\
\text { skunk }\end{array}$ & Conepatus humboldtii & $\mathrm{LC}$ & Stable & Banned & High \\
\hline Carnivora & Ansorge's cusimanse & Crossarchus ansorgei & LC & Decreasing & Unregulated & Medium \\
\hline Carnivora & $\begin{array}{l}\text { Small toothed ferret } \\
\text { badger }\end{array}$ & Melogale moschata & $\mathrm{LC}$ & Stable & Unregulated & High \\
\hline Carnivora & Sable & Martes zibellina & $\mathrm{LC}$ & Increasing & Regulated & High \\
\hline Carnivora & Common genet & Genetta genetta & $\mathrm{LC}$ & Stable & Banned & Medium \\
\hline Carnivora & Fennec fox & Vulpes zerda & $\mathrm{LC}$ & Stable & Banned & High \\
\hline Carnivora & $\begin{array}{l}\text { Small toothed palm } \\
\text { civet }\end{array}$ & $\begin{array}{l}\text { Arctogalidia } \\
\text { trivirgata }\end{array}$ & LC & Decreasing & Banned & High \\
\hline Carnivora & American badger & Taxidea taxus & $\mathrm{LC}$ & Decreasing & Unregulated & Medium \\
\hline
\end{tabular}




\begin{tabular}{|c|c|c|c|c|c|c|}
\hline Carnivora & Gambian mongoose & Mungos gambianus & $\mathrm{LC}$ & Stable & Unregulated & High \\
\hline Carnivora & $\begin{array}{l}\text { Common slender } \\
\text { mongoose }\end{array}$ & Herpestes sanguineus & $\mathrm{LC}$ & Stable & Unregulated & High \\
\hline Carnivora & Striped skunk & Mephitis mephitis & $\mathrm{LC}$ & Stable & Regulated & High \\
\hline Carnivora & Hooded skunk & Mephitis macroura & $\mathrm{LC}$ & Increasing & Unregulated & High \\
\hline Carnivora & Puma & Puma concolor & $\mathrm{LC}$ & Decreasing & Regulated & Medium \\
\hline Carnivora & Northern hog badger & Arctonyx albogularis & $\mathrm{LC}$ & Decreasing & Unregulated & High \\
\hline Carnivora & Sumatran hog badger & Arctonyx hoevenii & $\mathrm{LC}$ & Stable & Unregulated & High \\
\hline Carnivora & Chilla & Lycalopex griseus & $\mathrm{LC}$ & Stable & Regulated & Medium \\
\hline Carnivora & $\begin{array}{l}\text { North american river } \\
\text { otter }\end{array}$ & Lontra canadensis & $\mathrm{LC}$ & Stable & Regulated & High \\
\hline Carnivora & Small indian civet & Viverricula indica & $\mathrm{LC}$ & Stable & Regulated & Medium \\
\hline Carnivora & American mink & Neovison vison & $\mathrm{LC}$ & Stable & Regulated & High \\
\hline Carnivora & Western spotted skunk & Spilogale gracilis & $\mathrm{LC}$ & Decreasing & Unregulated & High \\
\hline Carnivora & Greater grison & Galictis vittata & $\mathrm{LC}$ & Stable & Banned & Medium \\
\hline Carnivora & Black legged mongoose & Bdeogale nigripes & $\mathrm{LC}$ & Decreasing & Unregulated & High \\
\hline Carnivora & Ring tailed vontsira & Galidia elegans & $\mathrm{LC}$ & Decreasing & Unregulated & Medium \\
\hline Carnivora & Alexander's cusimanse & $\begin{array}{l}\text { Crossarchus } \\
\text { alexandri }\end{array}$ & $\mathrm{LC}$ & Decreasing & Unregulated & High \\
\hline Carnivora & Jungle cat & Felis chaus & LC & Decreasing & Banned & Medium \\
\hline Carnivora & Swift fox & Vulpes velox & $\mathrm{LC}$ & Stable & Banned & High \\
\hline Carnivora & Canada lynx & Lynx canadensis & $\mathrm{LC}$ & Stable & Regulated & High \\
\hline
\end{tabular}




\section{Appendix 7}

Comparison of mean population growth predictions from generalized additive models based on theoretical simulations and empirical data.

Our classification of IUCN Red List species enabled us to derive the proportion of all species showing a decreasing, stable and increasing population trend for each of the different combinations of decision-making bias and user compliance. We then assigned numerical values to each of the three population trends ( -1 for decreasing, 0 for stable and 1 for increasing) and modeled this variable as a function of the interaction between decision-making bias and user compliance using a generalized additive model with Gaussian error structure and tensor product smooth. This resulted in an interpolated surface showing mean population trajectory (from -1 to 1) as a function of decision-making bias and user compliance classifications. This surface was then compared to the theoretical surfaces obtained using growth rates of $0.1,0.2$ and 0.3 (see main text and Figure A4.1).

Figure A6.1 shows the relationship between predictions based on theoretical and empirical data for the different tested growth rates and how it compares to the $\mathrm{x}=\mathrm{y}$ line (i.e. perfect match). The overall deviation from the $\mathrm{x}=\mathrm{y}$ line is low for theoretical growth rates of 0.1 and 0.2 as these values are more representative of the growth rates found in the IUCN species considered (Anseriformes, Carnivore and Certatiodactlya). 

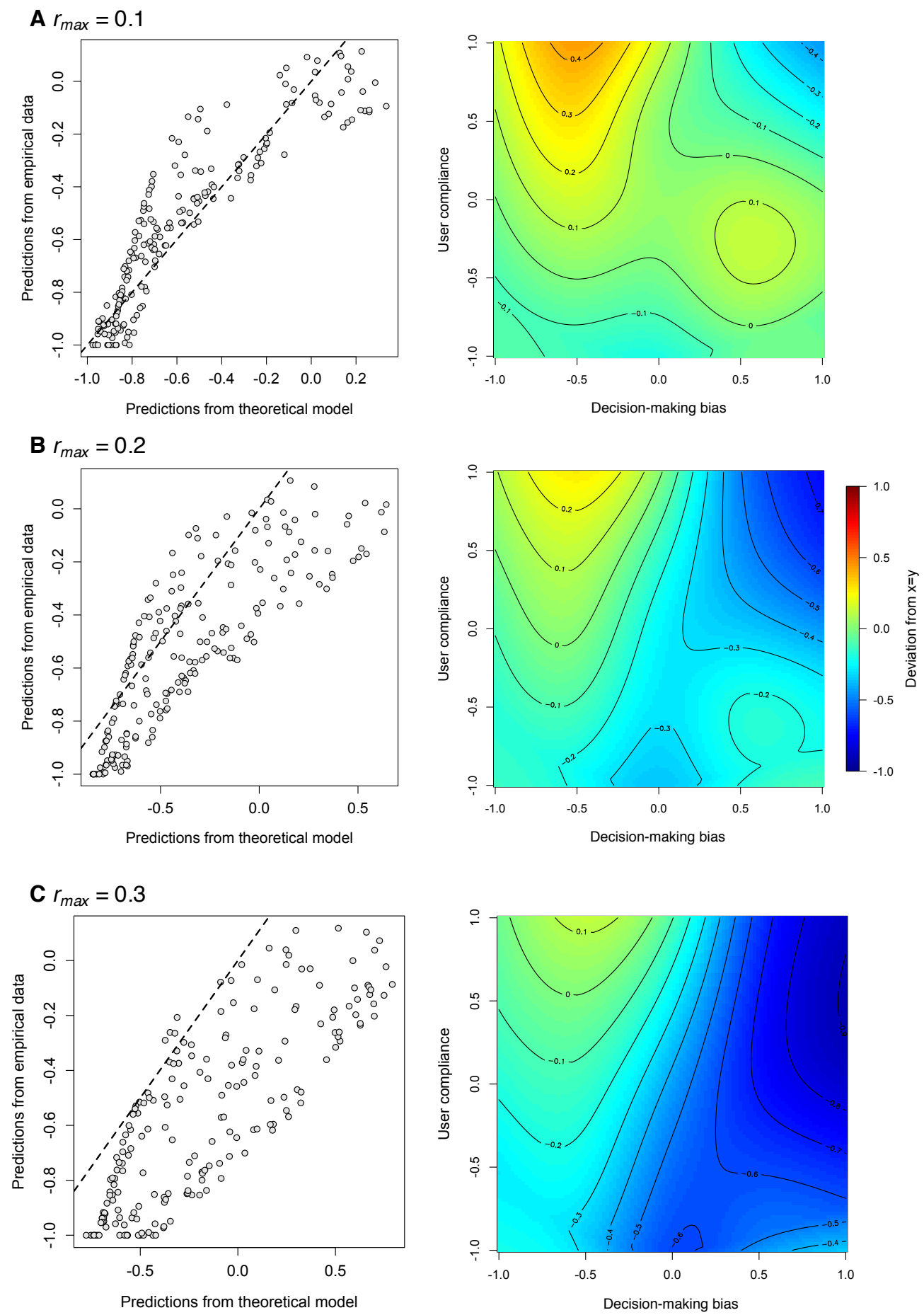

Fig. A7.1. Comparisons are shown for simulated intrinsic population growth rates of 0.1, 0.2 and 0.3. In each case, full grey circles denote a set of 200 random prediction coordinates, and the dashed line represents the $x=y$ line. $2 \mathrm{D}$ contour plots show the 
deviation from the $\mathrm{x}=\mathrm{y}$ line for varying levels of decision-making bias $(-1=$ pro-user interests, $0=$ unbiased and $+1=$ pro-conservation interests $)$ and user compliance $(-1=$ low compliance, $0=$ medium compliance and $+1=$ high compliance) . 